\title{
Isaac Newton's Microtonal Approach to Just Intonation
}

\author{
DANIEL MUZZULINI [1] \\ Institute for Computer Music and Sound Technology, Zurich University of the Arts (ZHdK)
}

\begin{abstract}
In 1665 Isaac Newton wrote a notebook in which he collected materials for a musical treatise which was never completed. He investigated ways of approximately representing just intonation scales by dividing the octave into many equally sized intervals. Strictly speaking, equal divisions of the octave are incompatible with just intonation, and just intonation intervals are audibly different from the intervals played on a modern equally tempered modern piano. By increasing the number of parts of an equal division, just intonation can be approximated arbitrarily well. Scales with more than 60 microtonal steps per octave, however, never gained wide acceptance in music theory or practice. Newton divided the octave into 612 equal parts so that he could represent the syntonic chromatic scale very accurately and he studied several equal divisions of the octave with fewer parts. His approximation problem is looked at in three ways: (1) A reconstruction of how he determined the many EDO-representations listed in the notebook is given. (2) Using computer programs Newton's tuning problem is solved "empirically" through calculating and evaluating the related approximations comprehensively. (3) The findings from the computer-assisted analysis are used to develop a more general geometric approach to the approximation problem.
\end{abstract}

Submitted 2020 April 30; accepted 2021 February 22.

Published 2021 June 28; https://doi.org/10.18061/emr.v15i3-4.7647

KEYWORDS: just intonation, equal division of the octave, logarithmic approximation

ISAAC Newton (1643-1727) is known for his outstanding contributions to mathematics and physics. In the 1660s he invented the mirror telescope and developed the basics of the theory of ray optics published in Opticks (1704). His early contributions to music theory are less known and were not published during his lifetime. A college notebook from 1665 contains the draft of a music theoretical treatise, which has been recently edited critically by Benjamin Wardhaugh [2]. Newton's manuscript contains two circular diagrams which are inspired by Descartes's Compendium Musicae (1650). Newton's diagrams interpret and generalize Descartes's just intonation hexachordal system through octave divisions into 53 and into 120 equal parts, see Figure 2. The idea to approach just intonation through 53-EDO [3] was brought about by Nicolaus Mercator at about the same time - also in manuscripts, see Wardhaugh (2013, pp. 129-236). Due to an early quotation by William Holder (1694/1730, pp. 79-80) Mercator's treatment of the tuning problem is better known than Newton's note book. Besides the mentioned divisions Newton considered several other equal division of the octave (EDOs) with respect to their capacity to approximate just intonation tunings. These EDOs are in the focus of this article.

After a brief introduction into Pythagorean and just intonation tunings, I will give some remarks on the construction of syntonic chromatic scales in historical sources. The following close reading of Newton's sketchy note book tries to clarify why he studied certain octave divisions and neglected others.

In order to tackle Newton's optimization problem with modern means, I calculated the closest approximation to Newton's syntonic chromatic scale for all equal divisions of the octave with up to 5000 microtonal steps per octave and analysed them in terms of least square deviations and consistency. This analysis helps to assess Newton's selection of octave divisions systematically and it leads us to a general approach to the tuning problem and to an elegant description of the dependence of the best fits from the fineness of the approximating scales, i.e., their number of equal steps per octave.

The use of least square deviations to assess the quality of best fit approximation problems is a mathematical standard with many applications in data analysis, especially in statistics and probability theory. In the $19^{\text {th }}$ century it was applied to musical scales by Drobisch (1852, pp. 75-78) and more recently by James 
M. Barbour (1951) and Johannes Barkowsky (2007, p. 105). Barbour's approach, which takes 12-EDO as a reference scale to assess chromatic and enharmonic scales, was criticized by Donald Hall (1973).

The approximation problem studied in this article is not of a genuinely stochastic nature, because the content of the datasets generated by computer programs are uniquely determined. Nevertheless, they appear to the eye as a kind of random data. The knowledge of three excellent $n$-EDO representations of the syntonic chromatic scale, 53-EDO, 118-EDO and 612-EDO, explains the quasi-chaotic dependence of the quality of best fit on $n$ for values of $n$ up to 1200 very well. In other words, for EDOs with unit steps not smaller than 1 cent, the discrete interval configuration of the just intonation scale and the approximating space are both three-dimensional. [4] Newton had accurate tables of (base 10) logarithms at his disposal and he used them to measure just intonation intervals with 12-EDO semitones, but he had no powerful computers and software. The "empirical" approach to Newton's approximation problem given here is in line with his selection of octave divisions and it reveals general properties of equal octave division and their capacity to simulate just intonation tuning by combining them linearly.

\section{JUST INTONATION: LIMIT-3 AND LIMIT-5 TUNING}

Pythagorean music theory is based on the idea that musical intervals can be described with ratios of small positive integers. In antiquity these ratios refer to string lengths on a monochord. [5] The diatonic genus and the related pitch systems of the Pythagoreans, as passed down to the Middle Ages and the Renaissance, can be defined by ratios of numbers which have only 2 and 3 in their prime number factorisations. In modern terminology and notation, the so-called "Pythagorean tuning" [6] is given by rational numbers of the format $2^{k} \cdot 3^{j}$ where $k$ and $j$ are integers (positive, zero or negative). The set of numbers $L_{3}:=\left\{2^{k} \cdot 3^{j} \mid k, j \in \mathbb{Z}\right\}$ is a dense subset of the real numbers, which hereafter is called limit-3 tuning (system). Finite subsets of $L_{3}$ can be used to define the Pythagorean intervals, chords and scales.

Historical sources often describe pitch sets with multi-terms proportions of integers and visualize them on monochord drawings. In order to describe an octave periodic scale or chord, the first and last element of the related proportion are of the ratio $2: 1$. The Pythagorean proportion

$$
6: 8: 9: 12=\left(2^{1} \cdot 3^{1}\right):\left(2^{3} \cdot 3^{0}\right):\left(2^{0} \cdot 3^{2}\right):\left(2^{2} \cdot 3^{1}\right)
$$

for example, serves as a reference frame for the Greek diatonic, chromatic and enharmonic genera. Pitch systems from the late Renaissance and later periods are usually strictly octave periodic. However, this is not necessarily the case in the Middle Ages and antiquity. [7]

Syntonic tunings or limit-5 tunings are defined in the same way with the sole prime factors 2, 3 and 5, and limit-7 tunings with the prime factors 2, 3, 5 and 7:

$$
L_{5}:=\left\{2^{k} \cdot 3^{j} \cdot 5^{i} \mid k, j, i \in \mathbb{Z}\right\}, L_{7}:=\left\{2^{k} \cdot 3^{j} \cdot 5^{i} \cdot 7^{h} \mid k, j, i, h \in \mathbb{Z}\right\}
$$

Limit-5 tunings can be constructed by combining octaves $(2: 1)$, Pythagorean fifths $(3: 2)$ and (just) major thirds $(5: 4)$. [8] Limit-7 tunings also permit "just minor sevenths" (7:4), but normally without piling them, so that the value of the power index $h$ in the formula for $L_{7}$ equals $-1,0$ or 1. Limit-7 tunings were suggested by several theorists from the $17^{\text {th }}$ to the $20^{\text {th }}$ century, among them Christiaan Huygens (c. 1661) and Quirinius van Blankenburg (1739), see Jedrzejewski (2018). Musicians referring to "just intonation" usually mean limit-5, but sometimes also limit-7 tuning. In this text we frequently use the term "syntonic scales" for subsets of $L_{5}$. [9]

Octaves, Pythagorean fifths and just major thirds are base vectors of a three dimensional "interval space" $\mathbb{Z}^{3}=\{(k, j, i) \mid k, j, i \in \mathbb{Z}\}$ defined by the power indices from $L_{5}$. Because of the uniqueness of the prime factorization there is a natural embedding:

$$
\mathbb{Z}^{3}=\{(k, j, i) \mid k, j, i \in \mathbb{Z}\} \cong L_{5} \subset \mathbb{Q} \subset \mathbb{R}
$$

Hereby, different points in $\mathbb{Z}^{3}$ correspond to different frequency ratios and arbitrary irrational numbers can be approximated arbitrarily well through limit-5 ratios, which means that $L_{5}$ is a dense subset of the real numbers $\mathbb{R}$. 
Nicolas Mercator in the $17^{\text {th }}$ century was probably the first to represent limit-5 tunings with twodimensional grids which abstract from the octave coordinate [10]. Jean-Philippe Rameau (1726), Leonhard Euler (1739) and others in the $18^{\text {th }}$ century used the same technique to visualize scales and chords on a twodimensional lattice. The number triangles used by Boethius, Torkesey and their followers up to Robert Fludd in the early $17^{\text {th }}$ century are precursors of two-dimensional pitch grids; however, they do not abstract from octave similarity. [11] Isaac Newton did not use grid notation in order to describe just intonation tunings, which possibly means that he did not know Mercator's manuscripts when he studied EDOs. Newton favoured combinatorics and circular arrangements which he picked up from Descartes' Compendium Musicae, see Figures $1 \mathrm{~b}$ and $2 \mathrm{a}$.

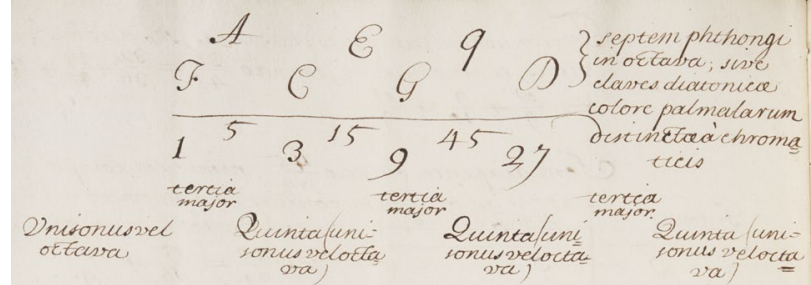

Figure 1a. Mercator's two-dimensional representation of the syntonic diatonic scale, together with the corresponding numbers composed of prime powers of 3 and 5 below the horizontal line - neglecting the octave information (Mercator, MS MUS. 1187 fol. 11v, by permission of the Christ Church Library, London)
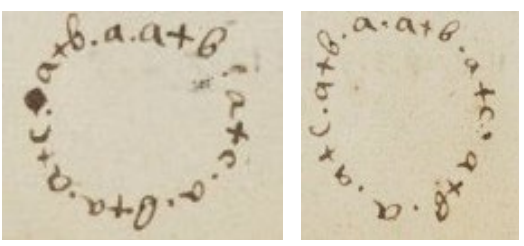

Figure $1 b$. Newton describes syntonic scales through three kinds of semitones, the diatonic semitone $a$, the greater chromatic semitone $b$ and the lesser chromatic semitone $c$, which he arranges on an octave circle (Newton 1665, fol. 110r).

\section{Incommensurable intervals: Euclid's algorithm and continued fractions}

The mathematical reason for the quasi-chaotic appearance of the datasets discussed below is the mutual incommensurability of the logarithms of the primes 2, 3 and 5 (expressed in any common base, conveniently 2). This incommensurability can be summarized with the following three formulas:

$$
\begin{aligned}
& \log _{2}(3) \in \mathbb{R} \backslash \\
& \log _{2}(5) \in \mathbb{R} \backslash \mathbb{Q} \\
& \log _{2}(5) / \log _{2}(3) \in \mathbb{R} \backslash \mathbb{Q}
\end{aligned}
$$

Being irrational numbers, these expressions cannot be written as integer ratios (ordinary positive fractions). Translated into music theory the first formula (i) is equivalent to the incommensurability of the just fifth and the octave so that chains of Pythagorean fifths modulo octave generate scales with potentially infinitely many pitches per octave. The second formula (ii) means that major thirds of the ratio $5: 4$ are incommensurable to the octave in the same sense. And the third formula (iii) states that just major thirds and fifths are also mutually incommensurable in terms of musical interval size. The fact that intervals of superparticular ratios are mutually incommensurable has been known since antiquity.

Historically, commensurability was tested with Euclid's algorithm, which provides a method to distinguish rational from irrational ratios of quantities: Euclid's algorithm terminates after finitely many iteration steps, if and only if the ratio of the quantities under consideration is rational. The Pythagoreans knew this fact and that the algorithm does not terminate if it is applied to the diagonal and the side of a regular pentagon. In other words, they proved that the so-called golden ratio is irrational [12]. The application of Euclid's algorithm onto pairs of musical intervals viewed as continuous quantities (like distances on a straight line) produces their continued fraction expansion as a by-product. If this expansion is finite, the intervals under consideration are commensurable, otherwise they are incommensurable. In the Sectio canonis, assigned to Euclid, it is shown that any different intervals with superparticular frequency ratios (integer ratios of the form $\frac{n+1}{n}$ ) are mutually incommensurable. Boethius knew this result and discussed a proof by Archytas [13]. Whereas the continued fraction expansion of the golden ratio, $\frac{\sqrt{5}+1}{1}$, is periodic with the simplest possible pattern $[1,1,1,1, \ldots]$, the interval ratios related for pairs of superparticular frequency ratios have infinite continued fractions expansions which do not exhibit simple regular patterns. [14] 


\section{NEWTON'S CHROMATIC SCALES AND HIS VARIOUS OCTAVE DIVISIONS}

Descartes's adaption of the hexachord system to just intonation and its reduction to octave classes, as well as Newton's extension of Descartes's approach, lead us to the problem of defining just-tuned diatonic and chromatic 12-note scales. Differently from the Pythagorean scales of the Middle Age, which offer only few alternatives, there was no consensus about the definition of a chromatic scale in just intonation in the $17^{\text {th }}$ and $18^{\text {th }}$ centuries. Various chromatic scales were proposed, which occupy different and incongruent regions in pitch grids for just intonation. [15].

\section{From syntonic hexachords to chromatic scales}

Guido of Arezzo's Micrologus (c. 1025) constructs a tone system with seven overlapping hexachords "ut-remi-fa-so-la", each of them of the same symmetric interval structure T-T-s-T-T, a Pythagorean diatonic semitone s $(256: 243)$ flanked on both sides by pairs of major tones $\mathrm{T}(9: 8)$. Guido of Arezzo placed these congruent hexachords at $\mathrm{ut}=\Gamma, \mathrm{C}, \mathrm{F}, \mathrm{G}, \mathrm{c}, \mathrm{f}$ and $\mathrm{g}$, so that his system comprises two octaves plus a major sixth $[\Gamma$, ee], where $\Gamma$, the lowest note of the system, is one octave below $G$, and ee, the highest note of the system one octave above e. There is no B-flat in the lowest octave, but B-flat and B in the middle and upper octaves.

The Pythagorean hexachord $\left(P y t h_{H e x}\right)$ can be completed to octachords $\left(P y t h_{O c t}\right)$, so that the octave is portioned into five tones and two diatonic semitones, see Table 1. For this purpose, the minor third $(32: 27)$ between the major sixth $(27: 16)$ and the octave, is divided into a Pythagorean semitone and a major tone, which results in two equivalent diatonic scales a Pythagorean fifth/fourth apart. Hence, the Pythagorean hexachord Pyth $\mathrm{Hex}_{\mathrm{X}}$ on $\mathrm{C}$ together with the transpositions by a fourth $(4: 3)$ and by a fifth $(3: 2)$ generate a limit-3 diatonic system of eight pitch classes, C-D-E-F-G-A-Bb-B, if the pitches are reduced to one octave. The pitches can be arranged as a stack of fourths B-E-A-D-G-C-F-Bb with the chromatic semitone Bb-B of the ratio $2187: 2048$, which is approximately $25 \%$ larger than the diatonic semitones E-F and Bb-B of the ratio $256: 243$.

Table 1. Pythagorean hexachords and octachords related to Guido of Arezzo's tone system.

\begin{tabular}{|c|c|c|}
\hline & Pythagorean hexachord & Pythagorean octachords \\
\hline Interval structure & T-T-s-T-T & $\begin{array}{l}\text { T-T-s-T-T-s-T } \\
\text { T-T-s-T-T-T-s }\end{array}$ \\
\hline \multirow{3}{*}{ Ratio structure } & $\overbrace{4 / 3}^{27 / 16}$ & $2 / 1$ \\
\hline & $\underbrace{9 / 8}_{81 / 8}, 256 / 243,9 / 8,9 / 8$ & 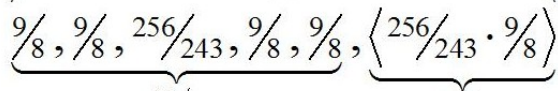 \\
\hline & $3 / 2$ & $32 / 27$ \\
\hline
\end{tabular}

Note: The two octachords are cyclic permutations of the same interval pattern. They define the same diatonic scale.

Guido's system was quoted time and again through the late Middle Ages and Renaissance up to the Templum musicae $(1618 / 24)$ by Robert Fludd (1618/24, p. 161) published immediately before René Descartes (1596-1650) composed the Compendium musicae dedicated to Isaac Beeckman (1619). The Compendium written 1618, the earliest complete treatise by Descartes, circulated in at least four manuscript copies during his lifetime, only 1650 immediately after his death it appeared in two Latin prints and three years later afterwards in an English edition (1653). Descartes's manuscript is lost. [16] One of the four circular pitch diagrams contained in the Compendium Descartes gives a system of three structurally identical hexachords "ut-re-mi-fa-so-la" (mollis, naturalis and duris), whose references are Pythagorean fifths apart as in Guido's system, but whose symmetric interval configuration t-T-S-T-t is composed of superparticular limit-5 ratios with major tones $\mathrm{T}(9: 8)$, minor tones $\mathrm{t}(10: 9)$ and diatonic semitones $\mathrm{S}(16: 15)$ in place of 
Guido's limit-3 intervals. Descartes's syntonic hexachord and its completions to octachords are shown in Table 2.

Table 2. Syntonic hexachords and octachords.

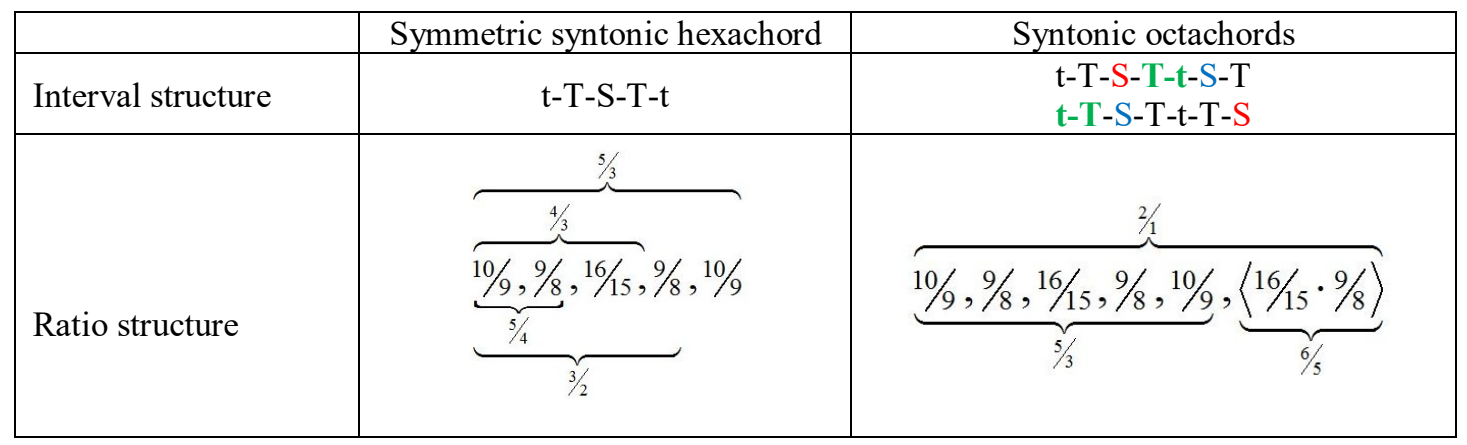

Note: The two ways of dividing the minor third between the sixth scale degree and the octave lead to two incongruent diatonic scales, in which the order of the major and minor tones between the respective tonics and their third scale degrees are reversed. Newton looked at both types of diatonic extensions, see Figures $2 \mathrm{c} / \mathrm{d}$.

Descartes' re-interpretation of Guido of Arezzo's Pythagorean hexachords results in a diatonic just intonation system with both varieties of B (B-duris and B-mollis) and two ambiguous pitches D and G, see Figure 1a. Just intonation as well as meantone temperaments were investigated and widely debated in the $16^{\text {th }}$ century by Fogliano (1529), Gioseffo Zarlino (1558/62, 1588), Francisco Salinas (1577) and Vincenzo Galilei (1581). Just intonation was usually justified by the consonance of the major thirds and by referring to Ptolemy's superparticular tetrachord divisions.

The use of concentric rings to visualize hexachordal tone systems has a very early forerunner in Theinred of Dover (Ms. Bodley 842, mid-twelfth or early fourteenth century), where four hexachords are represented on a circle that closes after two octaves, see Figure $2 b[17]$ Theinred's visualization was probably not known to Descartes, and almost certainly not to Newton. Descartes, however, was at least superficially familiar with Zarlino's theories from his college education at Flèche [18]. Zarlino's Sopplimenti musicali contain a diagram, which could have been a source of inspiration for one of Descartes's circular pitch diagrams, Zarlino (1588, Libro Ottavo p. 296). Newton in 1665 certainly knew either the English or more likely the Latin edition of Descartes's Compendium musicae, when he investigated musical scales.

Newton's constructions shown in Figures $2 \mathrm{c}$ and $2 \mathrm{~d}$ hold five seven-note scales (ut-re-mi-fa-sol-lafa) instead of the three Cartesian hexachords (ut-re-mi-fa-sol-la) with $u t=$ F-C-G-D-A and four ambiguous notes D, A, E and B. The hexachords of Figure 2c are equal to Descartes's (t-T-S-T-t) whereas in Figure 2d they are of the format T-t-S-T-t with a major tone $\mathrm{T}$ between ut and re. The numbers around the circle refer to 53-EDO and in Figure $2 \mathrm{~d}$ also to $120-\mathrm{EDO}$ (semitones to $1 \mathrm{~d}$.p.). The seventh grades fa, the minor sevenths with respect to ut, are indicated but not labeled in Figure 2c. Together Newton's five seven-note scales cover eleven out of twelve chromatic pitches (without $\mathrm{G} \# / \mathrm{Ab}$ ). 


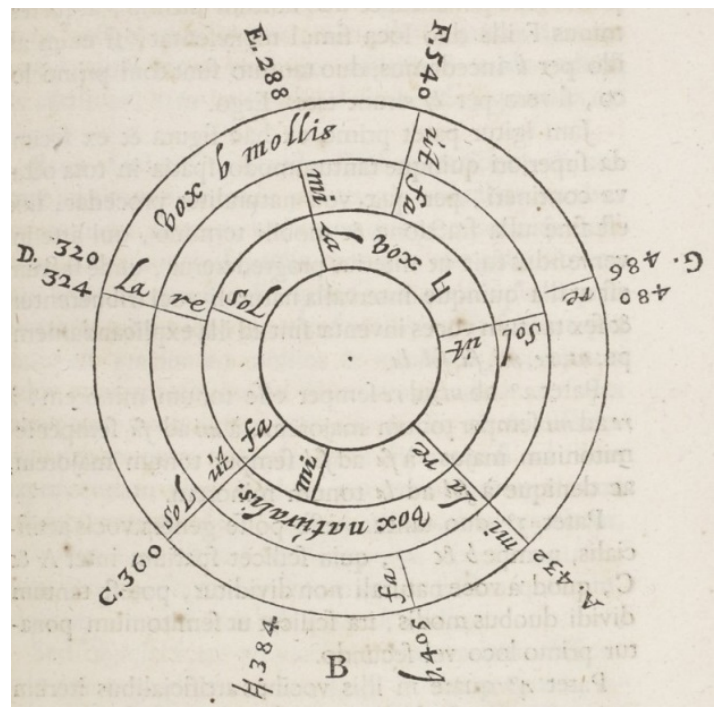

Figure 2a. Descartes' just intonation hexachords (ut-re-mi-fa-sol-la) with $u t=\mathrm{F}, \mathrm{C}$ and $\mathrm{G}$ result in two ambiguous notes, $\mathrm{G}$ and $\mathrm{D}$, differing by syntonic commas $(324: 320=80: 81=$ 486 : 480). (Descartes 1650, 35)

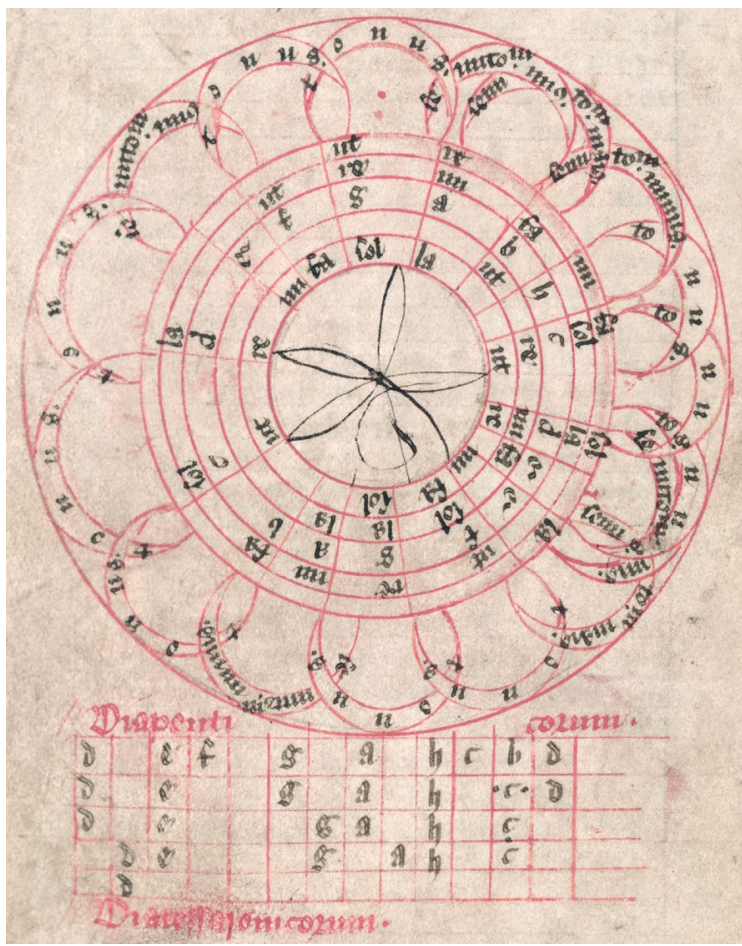

Figure $2 b$. Theinred of Dover's hexachords on a two-octave circle with four hexachords on $u t=\mathrm{Bb}$, $\mathrm{F}, \mathrm{C}, \mathrm{G}$ together with an interpretation in terms of a 12 semitone note frame without $\mathrm{F} \#$. The tuning is not specified, so that the diagram is compatible with Pythagorean as well as 12-EDO tuning, depending on the interpretation of the Tonus and Semitonium. (MS. Bodley 842, fol. 80v)

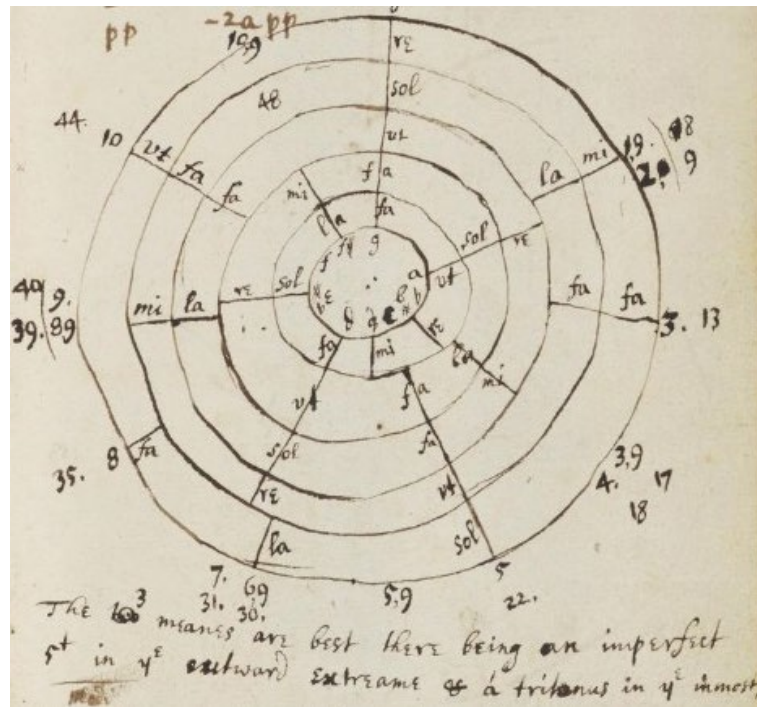

Figure 2d.

Figures $2 c / 2 d$. Newton's generalization of Descartes's hexachords (Newton 1665, fol. 110r, fol. 109r, MS Add. 4000: Reproduced by kind permission of the Syndics of Cambridge University Library). 


\section{Syntonic chromatic scales with 12 pitches per octave}

In his college notebook, Newton expressed the sizes of the syntonic intervals by 12-tempered semitones with an accuracy of 0.0001 cent (see Figure 8) [19]. There are various ways to select the pitches of a 12-note chromatic scale within $L_{5}$. The pitch sets from the Figures $2 \mathrm{c}$ and $2 \mathrm{~d}$ are inconsistent with Figures 3 and 8 , because the transpositions of the syntonic hexachord/scale by multiples of Pythagorean fifths generate configurations which are contained in two rows of fifths instead of three rows as in Figure 3.

Whereas Pythagorean chromatic scales have only two kinds of semitones, syntonic chromatic scales are composed of three or four differently sized semitones (see Figures 4 and 5). Newton's chromatic scale is equivalent to a scale proposed by Marin Mersenne (1636), and it has three kinds of semitones: seven diatonic semitones $a$ of the ratio $16: 15$, three greater chromatic semitones $\boldsymbol{b}$ of the ratio $135: 128$ and two lesser chromatic semitones $c$ of the ratio $25: 24$, producing the semitone pattern "a-b-a-c-a-b-a-a-c-a-b-a" with reference G, see Figures 3a/3b. It also contains a Pythagorean third F-A $(81: 64)$ defined through four Pythagorean fifths [20] so that the major triad F-A-C has a "mistuned" third compared with the perfect major triads on C, G and D of the G major scale. Holder's scale has five lesser chromatic semitones $(25: 24)$ but no greater chromatic semitones. Whereas the scales by Newton and Holder have only three different semitones, the solutions by Mercator and Euler require all four different semitones shown in Fig. 4. Euler's selection is equivalent to a configuration proposed by Athanasius Kircher (1650), and Newton's selection to a configuration by Marin Mersenne (1636). The earliest syntonic scale over three generations of fifths with precisely 12 pitch classes is by Kepler (1619). [21]

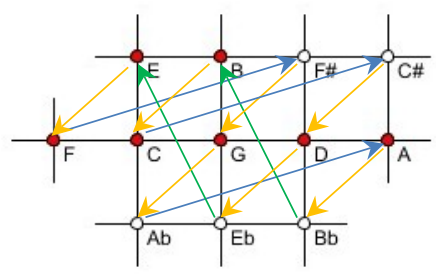

Figure 3a. Newton's syntonic chromatic scale in a rectangular pitch grid as a closed vector path. The notes (pitch classes) of the C-major scale are highlighted. The Gmajor scale is congruent with the standard diatonic major scale as described by Mercator, see Figure 1a.

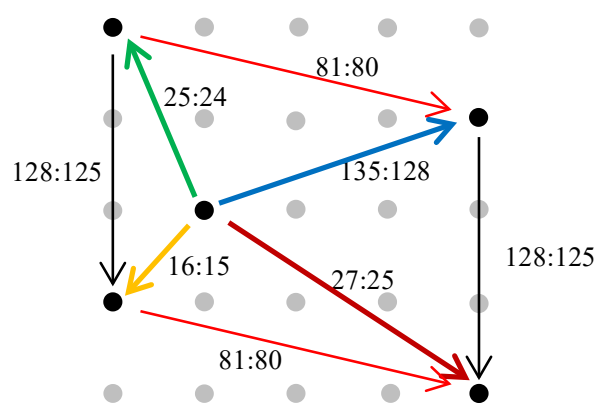

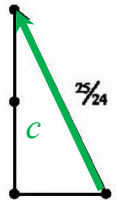

Figure $3 b$. The three kinds of semitones, $a, b$ and $c$, of Newton's chromatic scale together with their frequency ratios. The vector $b+a$ forms a major tone of the ratio $9: 8$, and $c+a$ forms a minor tone of the ratio $10: 9$, see also Figure $1 \mathrm{~b}$.

Figure 4. Vector representations of the four kinds of semitones occurring in limit-5 tunings. The lesser and greater chromatic semitones, as well as the ordinary and large diatonic semitones, differ by syntonic commas; the lesser chromatic and ordinary diatonic semitones, as well as the greater chromatic and large diatonic semitones, differ by enharmonic changes or major diesis $(128: 125)$ - an octave minus three just major thirds. 


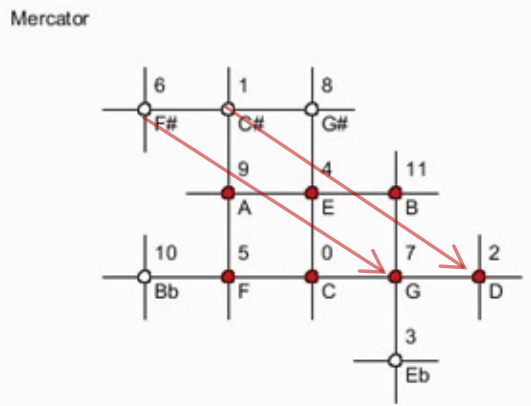

Newton

Holder
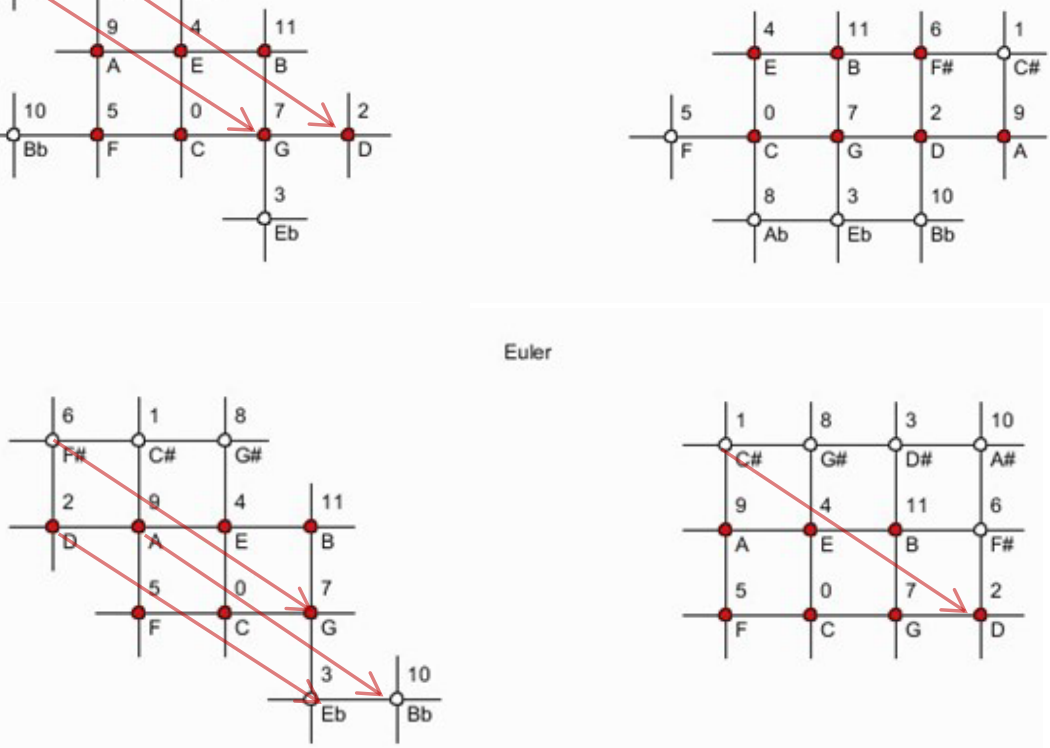

Euler

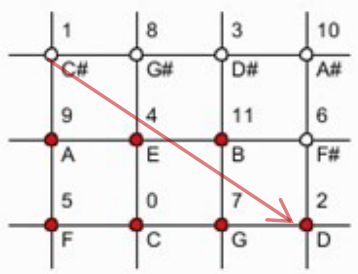

Figure 5. Grid representations of four different syntonic chromatic scales from historical sources. The large diatonic semitones $27: 25$ in the scales by Mercator (c. 1660), Holder (1694) and Euler (1739) are highlighted.

\section{2-EDO}

In his notebook, Newton examined the divisions of the octave into 15, 19, 20, 24, 25, 29, 36, 41, 51, 53, 59, 100, 120 and 612 equal parts in order to approximate the syntonic chromatic scale, see Figures 9a to 9d. How did he arrive at this particular selection of octave divisions, and how accurate are they? The most striking number is certainly 612, which results in a microtonal unit of little less than 2 cent. If a sound of $440 \mathrm{~Hz}$ [22] is increased by this tiny interval, its frequency increases by $0.5 \mathrm{~Hz}$ only. The algebraic key to this specific division of the octave can be found in Figure 6a.

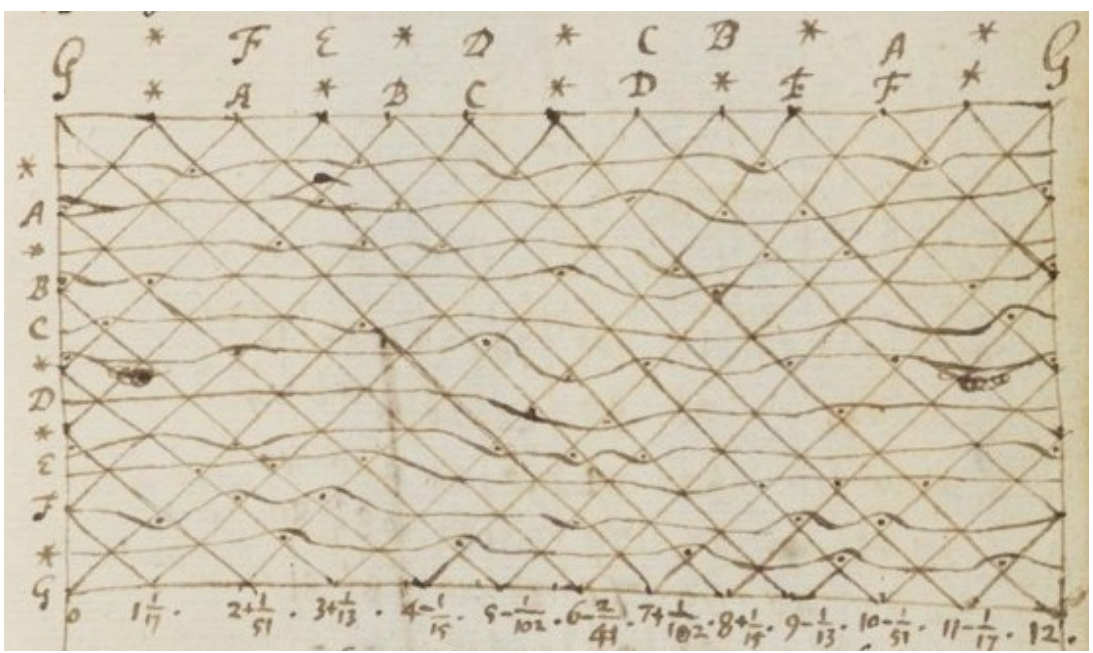

Figure $6 a$. The curves in the central part analyze all the intervals of the chromatic scale, whether they are greater or smaller than the corresponding intervals with respect to G. Newton $(1665,108 \mathrm{r})$ [23]. 


$$
\begin{array}{ccccccccccccc}
\mathrm{G} & * & \mathrm{~A} & * & \mathrm{~B} & \mathrm{C} & * & \mathrm{D} & * & \mathrm{E} & \mathrm{F} & * & \mathrm{G} \\
\mathrm{G} & * & \mathrm{~F} & \mathrm{E} & * & \mathrm{D} & * & \mathrm{C} & \mathrm{B} & * & \mathrm{~A} & * & \mathrm{G} \\
0 & 1+\frac{1}{17} & 2+\frac{1}{51} & 3+\frac{1}{13} & 4-\frac{1}{15} & 5-\frac{1}{102} & 6-\frac{1}{41} & 7+\frac{1}{102} & 8+\frac{1}{15} & 9-\frac{1}{13} & 10-\frac{1}{51} & 11-\frac{1}{17} & 12
\end{array}
$$

Figure $6 b$. Transcription of the note names and numbers from Figure 6a.

The "numbers" in Figure $6 \mathrm{a} / 6 \mathrm{~b}$ indicate sizes of the syntonic intervals with respect to $\mathrm{G}$ in terms of 12-EDO semitones plus/minus unit fractions of 12-EDO whole tones. The fractions not highlighted red or blue in the transcription permit the calculation of the 612-EDO representation of the pitch set G-Ab-A-C-DF-F\#-G containing optimum approximations of the Pythagorean sequence F-C-G-D-A as well as perfect minor and major triads F-Ab-C and D-F\#-A (spanning three rows of fifths), so that the overall quality of the approximation within the region of Newton's scale is made sure. Comparing the factorizations of the neighbored numbers 612,615 and 611 with the denominators in Figure $6 \mathrm{~b}(612=12 \cdot \mathbf{5 1}=36 \cdot \mathbf{1 7}, 615=$ $41 \cdot 15$ and $611=47 \cdot 13$ ) helps to understand why Newton preferred 612-EDO having a Pythagorean comma equivalent of 12 units, see also Appendix_1 (http://hdl.handle.net/1811/92832). The three groups of pitches defined by the denominators in Figure $6 \mathrm{~b}$ are highlighted in Figure 7 with the same colors. The denominators are symmetrically arranged about the tritonus/diminished fifth in the middle between $\mathrm{C}$ and $\mathrm{D}$. The denominator 41 makes Newton's scale slightly asymmetrical. The number 6 instead of $6-\frac{1}{41}$ would have meant perfect symmetry, but tritonus and diminished fifth cannot be equal in just intonation. [24] Making Newton's chromatic scale mirror symmetric in limit-5 tuning would require two different pitches $\mathrm{C} \#$ and $\mathrm{Db}$ $\left(6 \pm \frac{1}{41}\right)$, i.e., 13 pitches per octave. Newton addresses this point by giving two opposite scales in Figure 6 .

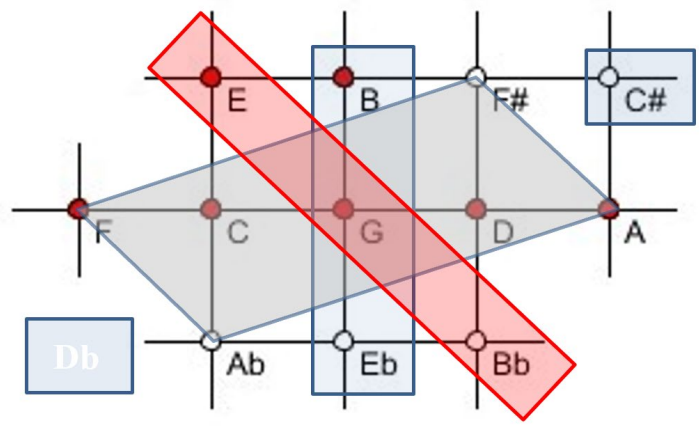

Figure 7. The 612-EDO pitches of the notes described in Figures $6 \mathrm{a} / \mathrm{b}$ correspond to pitches on and within the parallelogram F-Ab-A-F\#. The pitches $\mathrm{Db}, \mathrm{Eb}, \mathrm{G}, \mathrm{B}, \mathrm{C} \#$ fit to $615-\mathrm{EDO}$.

The intervals of Newton's chromatic scale in 612-EDO are shown in Table 3. Among the equal divisions of the octave looked at by Newton the division into 612 parts provides the most accurate approximation of the chromatic scale, not primarily because 612-EDO has the largest number of parts, but because the deviations of the best fit measured in unit intervals are the smallest. For example, 720-EDO is less accurate than 612-EDO, although it has a smaller unit interval [25].

\begin{tabular}{|c|c|c|c|c|c|c|c|c|c|c|c|c|}
\hline G & $\mathrm{Ab}$ & A & $\mathrm{Bb}$ & B & $\mathrm{C}$ & $\mathrm{C} \#$ & D & $\mathrm{Eb}$ & $\mathrm{E}$ & $\mathrm{F}$ & $\mathrm{F} \#$ & G \\
\hline 0 & 57 & 104 & 161 & 197 & 254 & 301 & 358 & 415 & 451 & 508 & 555 & 612 \\
\hline $\mathbf{0}$ & 56.983 & 103.994 & 160.977 & 197.020 & 254.003 & 301.014 & 357.997 & 414.980 & 451.023 & 508.006 & 555.017 & 612 \\
\hline
\end{tabular}

Table 3. Approximation of the syntonic chromatic scale in 612-EDO.

Note: The deviations to the decimal values ( 3 d.p.) in the last row, as calculated with logarithms, have a maximum of only 0.023 for $\mathrm{Bb}$ and $\mathrm{E}$.

Since Newton measured the deviations in unit fractions of 6-EDO units (whole tones) the denominators of the obtained rationalizations are necessarily multiples of 6 . Newton searched for good approximations with fewer parts than 612, and he probably wanted to make them independent of the 12 equally spaced semitones, which he used to measure the syntonic chromatic scale. He could achieve this by examining equal divisions of the octave with unit intervals which are multiples of the unit of 612-EDO like 
306-EDO, 204-EDO or 51-EDO determined by the divisors of 612. The 51-EDO unit is in the range of the pitch resolution of the human ear for pairs of successive tones and about the size of the Pythagorean comma. Newton's numbers for the chromatic scale in 51-EDO are on top of his list, shown in Figure 9b.

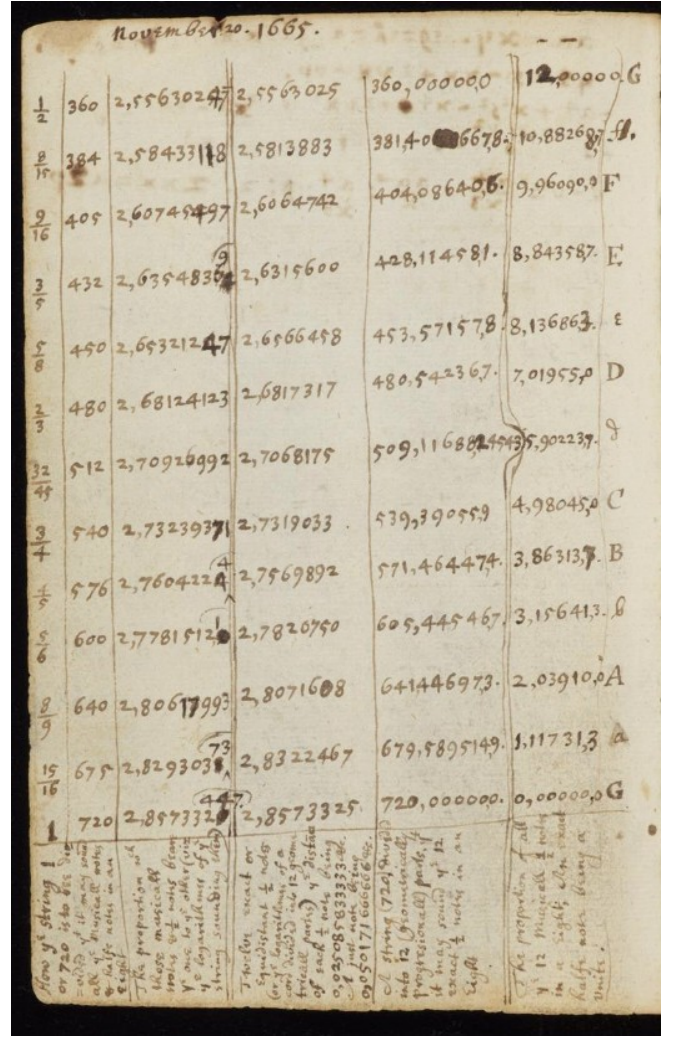

Figure 8. Newton gives base 10 logarithms of the intervals of the syntonic chromatic scale ( $3^{\text {rd }}$ column). The last number column expresses these intervals as multiples of 12-tempered semitones with an accuracy of 0.0001 cent. Newton $(1665,105 v)$

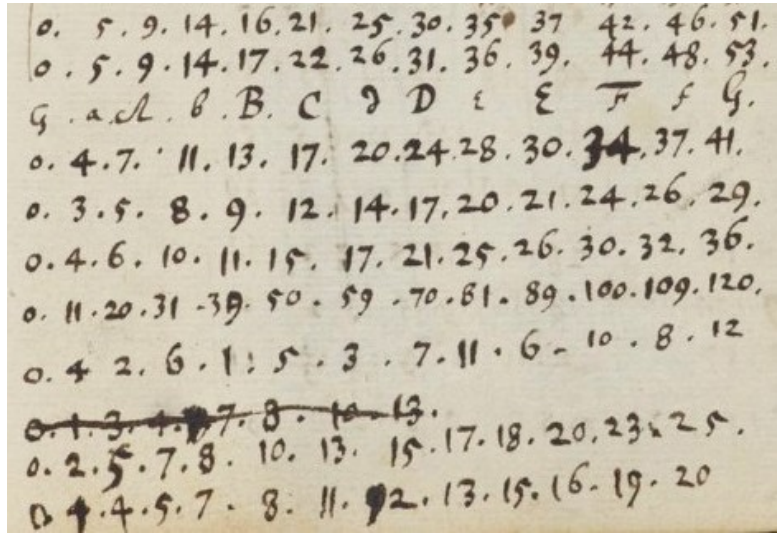

Figure $9 b$. It is unclear how the almost regular pattern in the fourth row from the bottom $\left(\begin{array}{lllllllllllll}0 & 4 & 2 & 6 & 1 & 5 & 3 & 7 & 11 & 6 & 10 & 8 & 12\end{array}\right)$ is related to the divisions of the octave. Newton $(1665,108 \mathrm{r})$

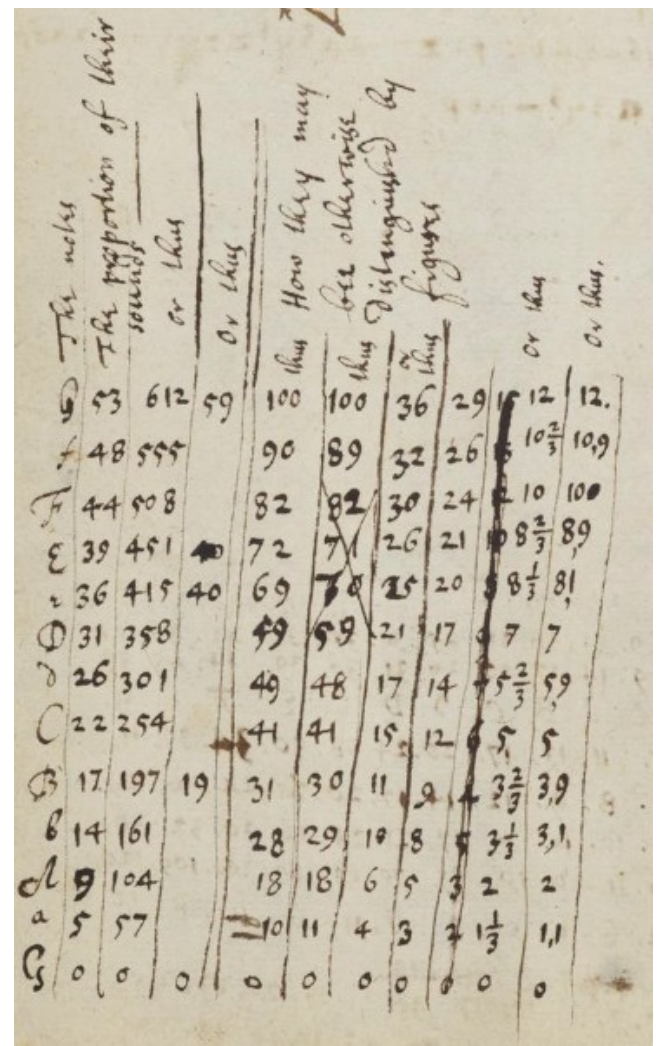

Figure $9 a$. The intervals of the syntonic chromatic scale approximated by multiples of unit intervals, which result from various divisions of the octave into equal parts.

Newton $(1665,108 v)$

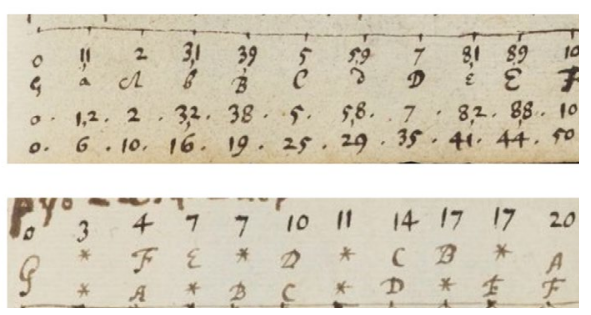

Figure 9c. Above: Two versions of 120 -EDO with semitones of the sizes $11,9,8$ resp. $12,8,6$ units, the latter are equivalent to 6, 4, 3 in 60-EDO. Newton (1665, 106r). Below: A 24EDO representation with a lesser chromatic semitone of size 0 . Newton $(1665,108 \mathrm{r})$. 
Why at all should one study tone systems with so many pitches per octave, if the smallest steps are imperceptibly small? From the end of the $15^{\text {th }}$ century to the early $20^{\text {th }}$ century many different limit- 5 chromatic and enharmonic systems with up to 53 pitches per octave have been proposed. Among the enharmonic scales given by Athanasius Kircher (1650) there is a scale with 38 pitches per octave, and Arthur von Oettingen (1917) depicts a selection of 53 limit-5 pitches. One reason for the study of fine grained "enharmonic" syntonic scales in the $16^{\text {th }}$ century was the wish to represent the Greek enharmonic tetrachords with their "quarter tones" in limit-5, see Zarlino $(1562,162)[26]$.

The analysis of the intervals in historical enharmonic scales with 22 or more pitch classes shows that they are much better represented in 118-EDO than in 53-EDO. Since 612-EDO is the coarsest tuning that accounts accurately and consistently for two differently sized commas - the Pythagorean and the syntonic with 12 and 11 units - it is the best base to study tunings which correspond to large coherent regions of the syntonic pitch grid. If the distinction between the Pythagorean and syntonic commas is irrelevant, 53-EDO with "Mercator comma"-units turns out to be the most convenient finite tuning for Pythagorean and syntonic scales. And two successive sounds distant by a Mercator comma are perceptibly different in pitch.To put it differently, whereas look-up tables for exponential functions and logarithms used in astronomy have many thousand entries to cover the range between 1 and 10, musical look-up tables require only 53, 118 or 612 entries to enable their user to calculate the ratios of arbitrary limit 5 -intervals within an octave with high precision. Jost Bürgi's exponential table (Bürgi 1620) has the base $1.0001=10^{1 / 23027.002 \ldots}=2^{1 / 6931.818 \ldots}$ so that it requires 6,932 entries to cover the range between 1 and 2 of a musical octave. Newton needed only the values of 12 base 10 logarithms, when he determined the optimum bases for musical logarithms and he did not even need numerical values for their bases, $2^{\frac{1}{53}} \approx 1.01316$ and $2^{\frac{1}{612}} \approx 1.00113$.

With similar intentions Aristoxenous divided the whole tone into sixty parts in order to compare the many varieties of the Greek diatonic, chromatic and enharmonic tetrachords suggested by different authors. The corresponding meta-system is $360-\mathrm{EDO}$, if the tone is interpreted as the sixth part of an octave as Vincenzo Galilei assumed (Galilei 1581, 58), so that historically Newton is not completely isolated with his fine-grained division of the octave.

\section{1-EDO and 53-EDO}

From the 612-EDO representation of the chromatic scale Newton could determine with fewer parts without extensive calculations. Taking the accuracy of 612-EDO for granted, it can be used to find coarser good equal divisions of the octave by proportionally reducing the 612-EDO representations. It follows from the previous paragraph that the irrational number $2^{1 / 612}$, the frequency ratio of the 612-EDO unit, can serve as the common ratio of a geometric series which approximates Newton's syntonic scale more accurately than any other equal division of the octave [27]. An idea for the varying quality of the approximations can be obtained by comparing the decimal parts of the numbers in the bottom row of Table 1 with the corresponding decimal parts in the bottom lines (labeled 'direct') of the following Tables 4 and 5 [28].

For finding the interval sizes of the 51-EDO scale one is tempted to divide the numbers in the 612EDO scale by 12 and round the results to the next integer, see the rows labeled "Newton" and "../12" in Table 4. Thereby, a simple rescaling is performed in order to calculate the pitches in 51-EDO from the 612-EDO pitches.

Newton's values for 51-EDO differ at two places from these rescaled values. This is not to be considered a mistake, since with Newton's values all the diatonic semitones (G-Ab, A-Bb, B-C, C\#-D, D$\mathrm{Eb}, \mathrm{E}-\mathrm{F}, \mathrm{F} \#-\mathrm{G})$ measure 5 units, the greater chromatic semitones (Ab-A, C-C\#, F-F\#) measure 4 and the lesser chromatic semitones (Bb-B, Eb-E) measure 2 units each. In other words, the two adjustments create a consistent scale, in which equal syntonic intervals are rendered with equal numbers of 51-EDO units: $7 \cdot 5+$ $3 \cdot 4+2 \cdot 2=51$

The major tones in Newton's 51-EDO scale measure 9 units so that six of them are 3 units larger than an octave. This difference, the 51-EDO equivalent of the Pythagorean comma, is three times as big as the Pythagorean comma [29], so that Newton's 51-EDO representation must be considered a very weak approximation to the syntonic chromatic scale. 
Table 4. Comparison of Newton's 612-EDO and 51-EDO chromatic scales.

\begin{tabular}{lccccccccccccc}
\hline & $\mathrm{G}$ & $\mathrm{Ab}$ & $\mathrm{A}$ & $\mathrm{Bb}$ & $\mathrm{B}$ & $\mathrm{C}$ & $\mathrm{C \#}$ & $\mathrm{D}$ & $\mathrm{Eb}$ & $\mathrm{E}$ & $\mathrm{F}$ & $\mathrm{F} \#$ & $\mathrm{G}$ \\
\hline Newton & 0 & 57 & 104 & 161 & 197 & 254 & 301 & 358 & 415 & 451 & 508 & 555 & 612 \\
..$/ 12$ & 0 & 4.8 & 8.7 & 13.4 & 16.4 & 21.2 & 25.1 & 29.8 & 34.6 & 37.6 & 42.3 & 46.3 & 51 \\
rounded & 0 & 5 & 9 & 13 & 16 & 21 & 25 & 30 & 35 & 38 & 42 & 46 & 51 \\
Newton & 0 & 5 & 9 & $\mathbf{1 4}$ & 16 & 21 & 25 & 30 & 35 & $\mathbf{3 7}$ & 42 & 46 & 51 \\
direct & 0 & 4.75 & 8.67 & 13.42 & 16.42 & 21.17 & 25.09 & 29.83 & 34.58 & 37.58 & 42.33 & 46.25 & 51 \\
\hline
\end{tabular}

Note: The pitch reference is $\mathrm{G}=0$ so that the size of the octave is either 612 or 51 units. Newton's 51-EDO representation differs at two places from simple rescaling. The last row in this table shows that rescaling from 612-EDO and direct logarithmic calculation result in the same integer approximations.

If instead only the 612-EDO sizes of the three semitones 57, 47, 36 are divided by 12 and rounded to the next integer, $\left(\frac{57}{12}, \frac{47}{12}, \frac{36}{12}\right) \approx(4.8,3.9,3) \approx(5,4,3)$, the division of the octave into 53 equal parts is obtained in a natural way because of $7 \cdot 5+3 \cdot 4+2 \cdot 3=53=6 \cdot 9-1$. In this partition of the octave both the syntonic and the Pythagorean comma measure one unit. The 53-EDO values of the chromatic scale can also be determined correctly by rescaling the 612 -EDO values with $\frac{53}{612}$ and rounding the results to the closest integer, see Table 5. The last row of the same table confirms that proportional rescaling gives the same numbers as the direct logarithmic computation. Furthermore, the maximum deviation in the best fit for 53-EDO is only 0.068 units (compared with 0.418 in 51-EDO).

Table 5. Derivation of 53-EDO from 612-EDO by rescaling as in Table 2.

\begin{tabular}{lccccccccccccc}
\hline & $\mathrm{G}$ & $\mathrm{Ab}$ & $\mathrm{A}$ & $\mathrm{Bb}$ & $\mathrm{B}$ & $\mathrm{C}$ & $\mathrm{C \#}$ & $\mathrm{D}$ & $\mathrm{Eb}$ & $\mathrm{E}$ & $\mathrm{F}$ & $\mathrm{F} \#$ & $\mathrm{G}$ \\
\hline Newton & 0 & 57 & 104 & 161 & 197 & 254 & 301 & 358 & 415 & 451 & 508 & 555 & 612 \\
..$*(53 / 612)$ & 0 & 4.9 & 9.0 & 13.9 & 17.1 & 22.0 & 26.1 & 31.0 & 35.9 & 39.1 & 44 & 48.1 & 53 \\
Newton & 0 & 5 & 9 & 14 & 17 & 22 & 26 & 31 & 36 & 39 & 44 & 48 & 53 \\
direct & 0 & 4.93 & 9.01 & 13.94 & 17.06 & 21.997 & 26.07 & 31.003 & 35.94 & 39.06 & 43.99 & 48.07 & 53 \\
\hline
\end{tabular}

\section{1-EDO and 29-EDO}

The representation of the chromatic scale in 41-EDO and 29-EDO can be directly obtained from the values of 53 -EDO by reducing the semitone sizes evenly, see Table 6 . The last row shows that the same procedure cannot be continued down to $17-\mathrm{EDO}$, since the related lesser chromatic semitones would have size zero.

Table 6. Arithmetic derivation of the values for 41-EDO and 29-EDO from 53-EDO.

\begin{tabular}{cccccccccccccc}
\hline & $\mathrm{G}$ & $\mathrm{Ab}$ & $\mathrm{A}$ & $\mathrm{Bb}$ & $\mathrm{B}$ & $\mathrm{C}$ & $\mathrm{C \#}$ & $\mathrm{D}$ & $\mathrm{Eb}$ & $\mathrm{E}$ & $\mathrm{F}$ & $\mathrm{F} \#$ & $\mathrm{G}$ \\
\hline 53-EDO & 0 & 5 & 9 & 14 & 17 & 22 & 26 & 31 & 36 & 39 & 44 & 48 & 53 \\
& -0 & -1 & -2 & -3 & -4 & -5 & -6 & -7 & -8 & -9 & -10 & -11 & -12 \\
41-EDO & 0 & 4 & 7 & 11 & 13 & 17 & 20 & 24 & 28 & 30 & 34 & 37 & 41 \\
& -0 & -1 & -2 & -3 & -4 & -5 & -6 & -7 & -8 & -9 & -10 & -11 & -12 \\
29-EDO & 0 & 3 & 5 & 8 & 9 & 12 & 14 & 17 & 20 & 21 & 24 & 26 & 29 \\
& -0 & -1 & -2 & -3 & -4 & -5 & -6 & -7 & -8 & -9 & -10 & -11 & -12 \\
17-EDO & 0 & 2 & 3 & $\mathbf{5}$ & $\mathbf{5}$ & 7 & 8 & 10 & $\mathbf{1 2}$ & $\mathbf{1 2}$ & 14 & 15 & 17 \\
\hline
\end{tabular}

Note: The semitone size numbers of 53-EDO are reduced by 1 or 2 units to obtain their values in 41-EDO and 29-EDO. A like reduction by 3 units to obtain 17-EDO would result in chromatic semitones Bb-B and Eb-E of size 0. 
This shows that there is no consistent scale with less than 29 units which distinguishes between the three kinds of semitones and preserves their natural order $\left(\frac{25}{24}<\frac{135}{128}<\frac{16}{15}\right)$ at the same time. Newton did not consider 65-EDO, 77-EDO and 89-EDO, although they can be derived from 53-EDO in the same way as 41-EDO and 29 -EDO, probably because they divide the octave into more parts and give less accurate approximations than 53-EDO.

\section{Overview and classification of Newton's EDOs}

The results of my analysis of the remaining scales studied by Newton are summarized in the following. Newton examined only divisions of the octave which assign fixed sizes to the three different semitones. Their sizes and the resulting minor and major tones are listed in Table 7.

Table 7. The sizes of the semitones and tones in Newton's various equal divisions of the octave.

\begin{tabular}{ccccccccccccccccc}
\hline$n$-EDO & 612 & 51 & 53 & 41 & 29 & 36 & 60 & 120 & 120 & 100 & 100 & 25 & 20 & 15 & 19 & 24 \\
\hline $25: 24(c)$ & 36 & 2 & 3 & 2 & 1 & 1 & 3 & 6 & 8 & 3 & 1 & 1 & 2 & $\mathbf{- 1}$ & $\mathbf{3}$ & 0 \\
$135: 128(b)$ & 47 & 4 & 4 & 3 & 2 & 2 & 4 & 8 & 9 & 8 & 7 & $\mathbf{3}$ & $\mathbf{3}$ & $\mathbf{1}$ & 2 & 1 \\
$16: 15(a)$ & 57 & 5 & 5 & 4 & 3 & 4 & 6 & 12 & 11 & 10 & 11 & 2 & 1 & 2 & 1 & $\mathbf{3}$ \\
$10: 9(t)$ & 93 & 7 & 8 & 6 & 4 & 5 & 9 & 18 & 19 & 13 & 12 & $\mathbf{3}$ & $\mathbf{3}$ & $\mathbf{1}$ & 4 & $\mathbf{3}$ \\
$9: 8(T)$ & 104 & 9 & 9 & 7 & 5 & 6 & 10 & 20 & 20 & 18 & 18 & 5 & 4 & 3 & $\mathbf{3}$ & 4 \\
\hline
\end{tabular}

Note: The numbers highlighted in the EDOs with $n=25$ or less indicate inconsistencies within the syntonic scale to be approximated.

Newton's 17 different EDOs can be classified as follows:

- $\quad 612,51,53,41,29:$ derivation from 612-EDO and 53-EDO

- 59: optimization of the major third or indirect derivation from 120-EDO or 53-EDO

- 24, 36, 60, 120: refinement of 12-EDO / 120: decimal division of the 12-EDO semitone

- 100, 25, 20: decimal division of the octave

- $15,19,20,24,25$ : small numbers (relative semitone sizes not respected)

Only, 29-EDO, 41-EDO, 53-EDO and 612-EDO, agree fully with the isolated rounding, which shows that Newton must have determined the representations of the scale by assigning fixed sizes to three independent intervals, e.g., to the three different semitones - at various places in the notebook he used the abbreviations $a, b$ and $c$ for the three semitones and $r, s, t$ for the major tone, the minor tone and the diatonic semitone. Also, the latter three intervals determine the corresponding approximation completely.

Newton did not consider the division into 118 equal parts, which is the closest approximation of his syntonic chromatic scale for octave division between 53-EDO and 612-EDO. He could have found this division, if he had investigated the rejected divisions into 59 parts or the division into 120 parts in greater detail. And he did not consider the accurate and consistent divisions into $65(=53+1 \cdot 12), 77(=53+2 \cdot 12)$ and $89(=53+3 \cdot 12)$ parts, perhaps because they use more parts than 53-EDO and are less accurate.

Without logarithms the divisions into 53 equal parts can be found by comparing the Pythagorean comma to the Pythagorean semitone, which are nearly in the size ratio $1: 4$. This approximate ratio was known by Boethius (1867, 293-295: Inst. Mus. III, 14) so that the whole tone, consisting of two Pythagorean semitones ("limmae") and a Pythagorean comma gives 9 units, and the octave - six tones minus a comma measures6 $6-9-1=53$ units, with a unit interval close to the Pythagorean comma. In fact, the octave measures 55.8 syntonic commas or 51.15 Pythagorean commas, so that Mercator's "artificial comma" is a good average between the two commas, being only marginally greater in magnitude (.475) than the true average'.This explains the accurate Pythagorean and syntonic intervals in 53-EDO.

The division of the octave into 53 equal parts was studied by Nicolaus Mercator at about the same time as Newton or even earlier [30]. As Benjamin Wardhaugh (personal communication, 2020) points out, it is not very likely that the two men exchanged ideas about tuning, since Newton at this time was still a student with no public profile. We do not know whether Newton, at the age of 22, was familiar with the aforementioned comparison of the Pythagorean comma to the semitone by Boethius [31]. 


\section{COMPUTATIONAL ANALYSIS OF ARBITRARY EDO-APPROXIMATIONS}

For the computer assisted analysis described in this section, I have created small Java programs with Processing. They generated lists of scales and key figures which I examined with spread sheets. One of these programs determined and analyzed the $n$-EDO approximations of limit-5 diatonic and chromatic scales for $n$ $<2000$, see Appendix_2 (http://hdl.handle.net/1811/92832). This analysis of the least square deviations can be related to Newton's octave divisions.

For this purpose, the diatonic and chromatic scales of just intonation are expressed with ratios to the reference notes $\mathrm{C}$ resp. $\mathrm{G}$ as follows. The syntonic diatonic scale (limit- 5 diatonic scale) has two alternative pitches for the second degree $\mathrm{D}$, so that both the major tone and the minor tone above the key $\mathrm{C}$ are present:

$$
\begin{array}{ccccccccc}
\mathrm{C} & \mathrm{D} & \mathrm{D} & \mathrm{E} & \mathrm{F} & \mathrm{G} & \mathrm{A} & \mathrm{B} & \mathrm{C} \\
1 & \frac{10}{9} & \frac{9}{8} & \frac{5}{4} & \frac{4}{3} & \frac{3}{2} & \frac{5}{3} & \frac{15}{8} & 2
\end{array}
$$

The two varieties of $\mathrm{D}$ differ by a syntonic comma $\mathrm{c}(81: 80)$. This selection is in accordance with Descartes's definition of the diatonic scale, with the symmetric pattern t-c-t-S-T-t-T-S with which Newton was familiar. The (syntonic) chromatic scale is taken from Newton's notebook (Figure 8) and defined by:

$$
\begin{array}{ccccccccccccc}
\mathrm{G} & \mathrm{Ab} & \mathrm{A} & \mathrm{Bb} & \mathrm{B} & \mathrm{C} & \mathrm{C \#} & \mathrm{D} & \mathrm{Eb} & \mathrm{E} & \mathrm{F} & \mathrm{F} & \mathrm{G} \\
1 & \frac{16}{15} & \frac{9}{8} & \frac{6}{5} & \frac{5}{4} & \frac{4}{3} & \frac{45}{32} & \frac{3}{2} & \frac{8}{5} & \frac{5}{3} & \frac{16}{9} & \frac{15}{8} & 2
\end{array}
$$

For a given value of $n$ (i.e., for the division of the octave into $n$ equal intervals), the program calculates the sizes of all the intervals $\frac{p}{q}$ with respect to the reference note (C resp. G) with the formula $n$. $\log _{2} \frac{p}{q}$ and rounds them to the next integer. In the following this procedure is called isolated (logarithmic) rounding, if all the intervals of the diatonic or chromatic scale are determined in this way, see Appendix_3 (http:/hdl.handle.net/1811/92832).

The column headed dev in the Tables 8 and 9 contain the root mean square (rms) deviations of $n \cdot \log _{2} \frac{p}{q}$ from the rounded values. This deviation is thus expressed in units of the corresponding $n$-EDO approximation. The last column dev_c contains the rms-deviation expressed in cent. The cent values naturally converge against 0 for increasing values of $n$, whereas the deviations with respect to the size of the unit intervals do not. In the following the latter is simply called deviation, if the context is clear, and the root mean square deviation measured in cent, is called cent-deviation.

Table 8. Syntonic diatonic scale.

\begin{tabular}{llrrrrrrrrrr}
\hline $\mathrm{n}$ & $\mathrm{C}$ & $\mathrm{D}$ & $\mathrm{D}$ & $\mathrm{E}$ & $\mathrm{F}$ & $\mathrm{G}$ & $\mathrm{A}$ & $\mathrm{B}$ & $\mathrm{C}$ & dev & dev_c \\
\hline 12 & 0 & 2 & 2 & 4 & 5 & 7 & 9 & 11 & 12 & 0.1135 & 11.35 \\
53 & 0 & 8 & 9 & 17 & 22 & 31 & 39 & 48 & 53 & 0.0460 & 1.04 \\
118 & 0 & 18 & 20 & 38 & 49 & 69 & 87 & 107 & 118 & 0.0373 & 0.38 \\
$\mathbf{5 5 9}$ & 0 & 85 & 95 & 180 & 232 & 327 & 412 & 507 & 559 & 0.0306 & 0.07 \\
612 & 0 & 93 & 104 & 197 & 254 & 358 & 451 & 555 & 612 & 0.0166 & 0.03 \\
1783 & 0 & 271 & 303 & 574 & 740 & 1043 & 1314 & 1617 & 1783 & 0.0152 & 0.01 \\
2513 & 0 & 382 & 427 & 809 & 1043 & 1470 & 1852 & 2279 & 2513 & 0.0134 & 0.006 \\
4296 & 0 & 653 & 730 & 1383 & 1783 & 2513 & 3166 & 3896 & 4296 & 0.0030 & 0.0008 \\
\hline
\end{tabular}

Note: The values in column dev form a monotonically decreasing sequence if indexed by $n$. There is no longer subset of indices $n$ from 12 to 5000 with this property. 
Table 9. Results from optimizing the full syntonic chromatic scale.

\begin{tabular}{cccccccccccccccc}
\hline $\mathrm{n}$ & $\mathrm{G}$ & $\mathrm{Ab}$ & $\mathrm{A}$ & $\mathrm{Bb}$ & $\mathrm{B}$ & $\mathrm{C}$ & $\mathrm{C \#}$ & $\mathrm{D}$ & $\mathrm{Eb}$ & $\mathrm{E}$ & $\mathrm{F}$ & $\mathrm{F} \#$ & $\mathrm{G}$ & $\mathrm{dev}$ & $\mathrm{dev} \mathrm{c}$ \\
\hline 12 & 0 & 1 & 2 & 3 & 4 & 5 & 6 & 7 & 8 & 9 & 10 & 11 & 12 & 0.1076 & 10.76 \\
53 & 0 & 5 & 9 & 14 & 17 & 22 & 26 & 31 & 36 & 39 & 44 & 48 & 53 & 0.0504 & 1.14 \\
118 & 0 & 11 & 20 & 31 & 38 & 49 & 58 & 69 & 80 & 87 & 98 & 107 & 118 & $\mathbf{0 . 0 3 2 5}$ & 0.33 \\
612 & 0 & 57 & 104 & 161 & 197 & 254 & 301 & 358 & 415 & 451 & 508 & 555 & 612 & $\mathbf{0 . 0 1 5 7}$ & 0.03 \\
1783 & 0 & 166 & 303 & 469 & 574 & 740 & 877 & 1043 & 1209 & 1314 & 1480 & 1617 & 1783 & 0.0156 & 0.01 \\
2513 & 0 & 234 & 427 & 661 & 809 & 1043 & 1236 & 1470 & 1704 & 1852 & 2086 & 2279 & 2513 & 0.0151 & 0.007 \\
3684 & 0 & 343 & 626 & 969 & 1186 & 1529 & 1812 & 2155 & 2498 & 2715 & 3058 & 3341 & 3684 & 0.0134 & 0.004 \\
4296 & 0 & 400 & 730 & 1130 & 1383 & 1783 & 2113 & 2513 & 2913 & 3166 & 3566 & 3896 & 4296 & 0.0024 & 0.0007 \\
\hline & & & & & & & & & & & & & & \\
\hline 559 & 0 & 52 & 95 & 147 & 180 & 232 & 275 & 327 & 379 & 412 & 464 & 507 & 559 & $\mathbf{0 . 0 3 5 8}$ & 0.08 \\
\hline
\end{tabular}

Note: The record $n=559$ at the bottom is found by the optimization of the diatonic scale (Table 8 ), but not in the optimization of the chromatic scale (Table 9).

The Tables 8 and 9 list optimal approximations with respect to the rms-deviation (dev) in the following sense. For all integers $k$ less than $n$ the deviation in $k$-EDO is greater than the deviation in $n$-EDO. For example, the smallest number for which the deviations of the chromatic and the diatonic scale are smaller than the deviations for 12 is 53 . And between 53-EDO and 118-EDO there is no equal division $k$-EDO with a deviation smaller than the deviation for 53-EDO. This procedure produces maximal monotonically decreasing sequences of deviations.

The rankings created by this optimization algorithm are very similar across all sets of syntonic pitches tested, which comprised the full chromatic and diatonic scales, the major triad and the combination of the diatonic semitone with the major and minor tones [32]. This is not totally unexpected, since the syntonic system (limit-5 tuning) is generated by Pythagorean fifths and syntonic major thirds (modulo octave). The deviations for the diatonic scale, the chromatic scale as well as major thirds and fifths (the perfect major triad) for $n=12$ to 133 are visualized in Figure 10.

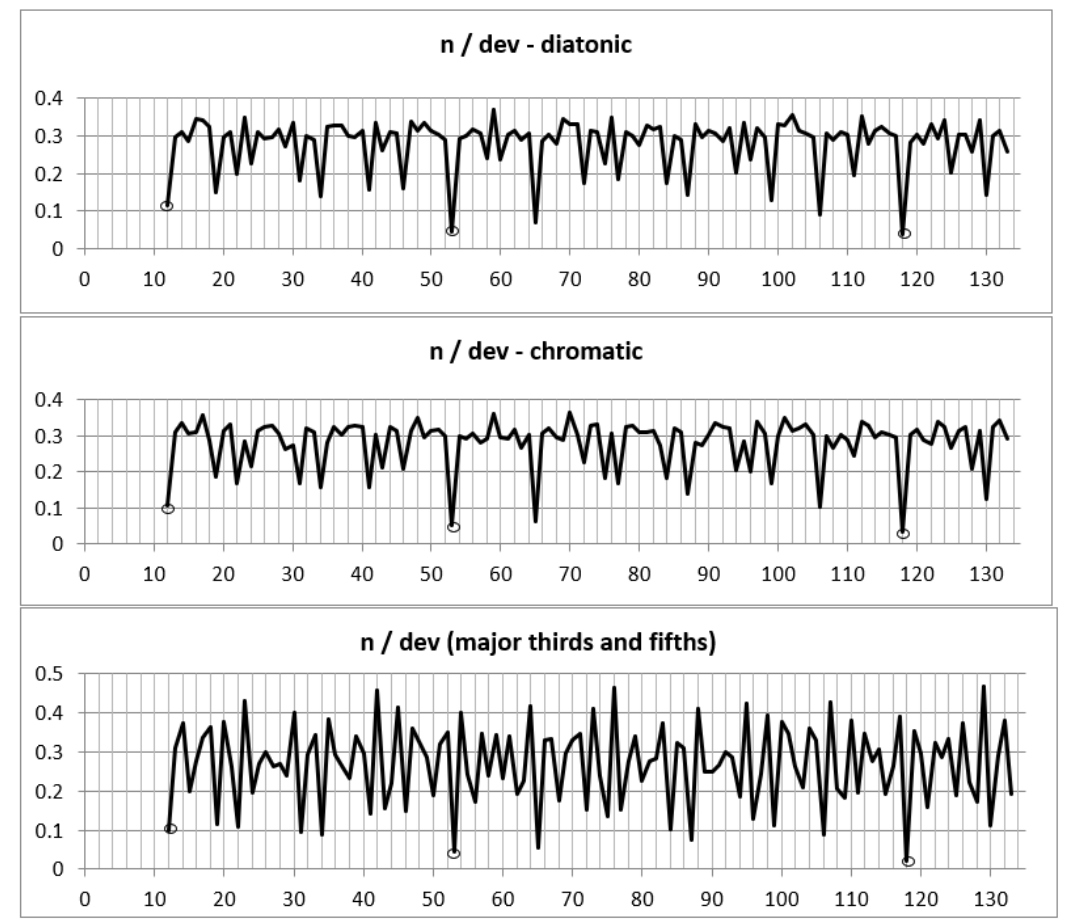

Figure 10. The rms-deviations of the diatonic scale, the chromatic scale and major triads (major thirds and fifths) for $n=12$ to 133 exhibit similar patterns. The minima for $n=12,53$ and 118 are highlighted with small circles. Notice that pronounced minima also occur at $n=53 \pm 12$ and at $n=118 \pm 12$. 


\section{Log-compatibility and consistency}

Newton's syntonic chromatic scale has three different semitones, the diatonic semitone (16:15 of 111.73 cent), the greater chromatic semitone ( $135: 128$ of 92.18 cent) and the lesser chromatic semitone $(25: 24$ of 70.67 cent). His scale with reference note $\mathrm{G}$ has seven diatonic semitones $a$, three greater chromatic semitones $b$ and two lesser chromatic semitones $c$, and the octave is filled by the semitone-pattern $a-b-a-c-a-b-a-a-c-a-$ $b-a[33]$.

In the following, a chromatic $n$-EDO scale is called consistent, if the semitones of the same kind are rendered as equal intervals, and it is called strongly consistent, if it is consistent and the condition $2 c>a>b$ $>c$ is satisfied, so that the relative size order of the three semitones is respected and the lesser chromatic semitone $c$ is greater than half a diatonic semitone $a$ [34]. Scales agreeing with the directly rounded logarithms are called log-compatible. The smallest positive integers $(a, b, c)$ with $2 c>a>b$ are $(5,4,3)$. With these values for $a, b$ and $c$ the 7 diatonic, the 3 greater and the 2 lesser chromatic semitones add up to an octave of 53 units $(53=7 \cdot 5+3 \cdot 4+2 \cdot 3)$. Since the isolated roundings of Newton's syntonic chromatic scale agree with the consistent 53-EDO representation, 53-EDO provides the coarsest strongly consistent and log-compatible chromatic scale.

In order to classify the chromatic scales for $n$ up to 1200 "consistency levels" as defined in Table 10 are used. Hereby, level 0 is equivalent with strong consistency. These definitions quantify the similarity of interval size relationships between the approximating EDO-scales and Newton's syntonic chromatic scale. The restrictions become gradually weaker for increasing consistency levels. True syntonic chromatic scales would have consistency level 0 , their approximation through 12 -EDO have consistency level 3 , because 12EDO does not distinguish between different semitones and has $a=b=c$.

Table 10. Definition of consistency levels for $n$-EDO scales.

\begin{tabular}{cl}
\hline cns-level & \multicolumn{1}{c}{ condition } \\
\hline 0 & $2 c>a>b>c$ \\
1 & $a>b>c$ and $2 c \leq a$ \\
2 & $a>b=c$ \\
3 & $a=b \geq c$ \\
4 & Not $a \geq b \geq c$ \\
\hline
\end{tabular}

Note: The variables $a, b$ and $c$ are the sizes of the diatonic, the greater chromatic and the lesser chromatic semitones.

For $n \leq 1200$ there are 374 divisions of the octave into $n$ equal intervals with log-compatible chromatic scales. The lowest deviations for scales with consistency levels $>0$ occurs at 12-EDO [35], 34EDO and 41-EDO. The maximum deviation occurs at 306-EDO $\left(306=\frac{1}{2} \cdot 612\right)$. 53-EDO and 65-EDO are the only divisions of the octave into less than 100 equal parts with a relative deviation lower than that of 12 EDO.

\section{3, 118 AND 612 - A GENERATOR SYSTEM AND ITS GEOMETRIC INTERPRETATION}

A close inspection of the numbers $n$ with small deviations between the best EDO fit and the syntonic chromatic scale reveals that they are in a close relationship to 612, 118 and 53, the numbers with the smallest relative deviations. The deviations for 53-EDO, 118-EDO and 612-EDO are visualized in Figure 11. The analysis of the data explored in this section shows that all the numbers $n$ up to 1200 with a log-compatible syntonic $n$-EDO scale can be written in the format $n=612 x+118 y+53 z$, where $x, y$ and $z$ are integers close to 0 . The number $n$ of the 32 scales with the lowest deviations can be written in this format with $0 \leq x \leq 2$, $-2 \leq y \leq 2$ and $-2 \leq z \leq 1$. 


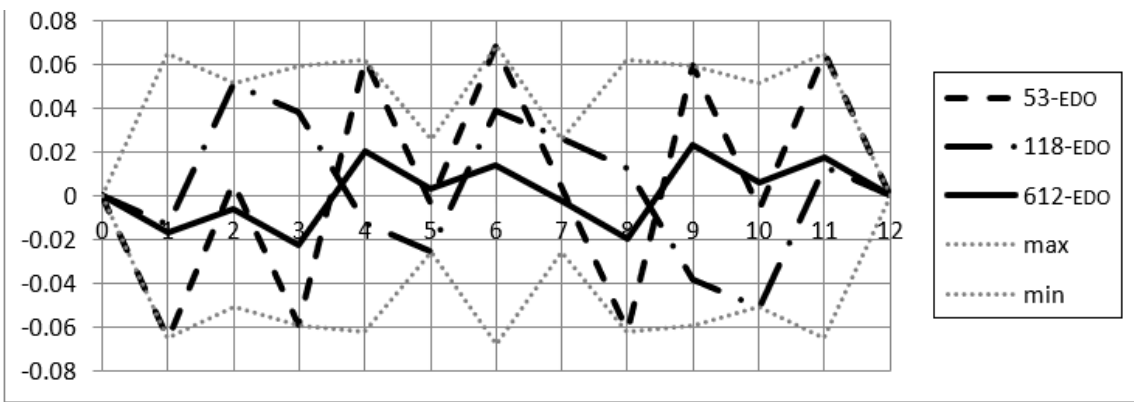

Figure 11. Relative deviations of the best fit for 53-EDO, 118-EDO and 612-EDO. The notes of the chromatic scale are numbered in horizontal direction from 0 to 12 with pitch reference $G=0,12$. 118-EDO has smallest deviations for minor second (1), major third (4), minor sixth (8) and major seventh (11) and greatest deviations for major second (2), fourth (5), fifth (7) and minor seventh (10). The envelopes $\min / \max$ refer to absolute values.

Therefore 53-EDO, 118-EDO and 612-EDO form a kind of generator system for log-compatible consistent scales. More precisely, the correct sizes of the $n$-EDO intervals can be linearly combined from the corresponding sizes in 53-EDO, 118-EDO and 612-EDO for all log-compatible scales with $n \leq 1200$.

If a given $n$ can be written as $n=612 x+118 y+53 z$, where $-1 \leq x \leq 3,-9 \leq y \leq 10$ and $-8 \leq z \leq$ 7 , the $n$-EDO sizes of the diatonic semitone $a$ and the chromatic semitones $b$ and $c$ can be calculated with the formulas $a=x \cdot 57+y \cdot 11+z \cdot 5, b=x \cdot 47+y \cdot 9+z \cdot 4$ and $c=x \cdot 36+y \cdot 7+z \cdot 3$ so that the sizes of the three semitones $a, b$ and $c$ are uniquely determined and hence the entire chromatic scale. In other words, the $\log$-compatible $n$-EDO representation (for arbitrary values of $n \leq 1200$ ) of the syntonic chromatic scale can be determined without using logarithms - just on base of the values of 53-EDO, 118-EDO and 612-EDO. The main task for a given $n$ is to express it as a suitable linear combination of 612, 118 and 53. Parts of the results of the corresponding calculations are shown in Table 11.

The following example uses $n=935$ and shows how the $n$-EDO representations of Newton's chromatic scale can be calculated by hand from the first four columns of Table 11: Because 935 can be written as $935=2 \cdot 612-2 \cdot 118-1 \cdot 53$ the coordinates for 935-EDO ( $\mathrm{dev} \operatorname{rank} 21)$ are $(x, y, z)=$ $(2,-2,-1)$ By substituting them into the formulas

$$
\begin{aligned}
& a=x \cdot 57+y \cdot 11+z \cdot 5 \\
& b=x \cdot 47+y \cdot 9+z \cdot 4 \\
& c=x \cdot 36+y \cdot 7+z \cdot 3
\end{aligned}
$$

the sizes of the 935-EDO semitones can be obtained as follows:

$$
\begin{aligned}
& a=2 \cdot 57+(-2) \cdot 11+(-1) \cdot 5=87 \\
& b=2 \cdot 47+(-2) \cdot 9+(-1) \cdot 4=72 \\
& c=2 \cdot 36+(-2) \cdot 7+(-1) \cdot 3=55
\end{aligned}
$$

With these values of $a, b$ and $c$ and the semitone-pattern $a-b-a-c-a-b-a-a-c-a-b-a$ the calculation of the 935EDO representation of Newton's chromatic scale can be calculated as a cumulative sum:

$$
\begin{aligned}
& a=87 \\
& a+b=87+72=129 \\
& a+b+a=129+87=246 \\
& a+b+a+c=246+55=301 \\
& \cdots
\end{aligned}
$$


Table 11. Coordinates $(x, y, z)$ of the numbers $n$ up to 1200 (where $n=x \cdot 612+y \cdot 118+z \cdot 53$, related semitone sizes $(a, b, c)$ and chromatic scales ordered according to deviations in $n$-EDO units (see Appendix_4 (http://hdl.handle.net/1811/92832) for the complete data).

\begin{tabular}{|c|c|c|c|c|c|c|c|c|c|c|c|c|}
\hline $\mathrm{n}$ & $\mathrm{x}$ & $\mathrm{y}$ & $\mathrm{z}$ & rnk & a & $\mathrm{b}$ & c & scale & dev_u & cmpt & cns & $\begin{array}{l}\mathrm{dev}_{-} \\
\mathrm{rnk}\end{array}$ \\
\hline 612 & 1 & 0 & 0 & 1 & 57 & 47 & 36 & $\begin{array}{lllllllllllll}0 & 57 & 104 & 161 & 197 & 254 & 301 & 358 & 415 & 451 & 508 & 555 & 612\end{array}$ & 0.0157 & 0 & 0 & 1 \\
\hline 1171 & 2 & 0 & -1 & 5 & 109 & 90 & 69 & $\begin{array}{lllllllllllll}0 & 109 & 199 & 308 & 377 & 486 & 576 & 685 & 794 & 863 & 972 & 1062 & 1171\end{array}$ & 0.0227 & 0 & 0 & 2 \\
\hline 730 & 1 & 1 & 0 & 2 & 68 & 56 & 43 & $\begin{array}{lllllllllllllll}0 & 68 & 124 & 192 & 235 & 303 & 359 & 427 & 495 & 538 & 606 & 662 & 730\end{array}$ & 0.0306 & 0 & 0 & 3 \\
\hline 118 & 0 & 1 & 0 & 1 & 11 & 9 & 7 & $\begin{array}{lllllllllllll}0 & 11 & 20 & 31 & 38 & 49 & 58 & 69 & 80 & 87 & 98 & 107 & 118 \\
\end{array}$ & 0.0325 & 0 & 0 & 4 \\
\hline 559 & 1 & 0 & -1 & 2 & 52 & 43 & 33 & $\begin{array}{lllllllllllll}0 & 52 & 95 & 147 & 180 & 232 & 275 & 327 & 379 & 412 & 464 & 507 & 559\end{array}$ & 0.0358 & 0 & 0 & 5 \\
\hline 494 & 1 & -1 & 0 & 2 & 46 & 38 & 29 & $\begin{array}{lllllllllllll}0 & 46 & 84 & 130 & 159 & 205 & 243 & 289 & 335 & 364 & 410 & 448 & 494 \\
\end{array}$ & 0.0408 & 0 & 0 & 6 \\
\hline 1053 & 2 & -1 & -1 & 6 & 98 & 81 & 62 & $\begin{array}{llllllllllllll}0 & 98 & 179 & 277 & 339 & 437 & 518 & 616 & 714 & 776 & 874 & 955 & 1053\end{array}$ & 0.0462 & 0 & 0 & 7 \\
\hline 677 & 1 & 1 & -1 & 3 & 63 & 52 & 40 & $\begin{array}{lllllllllllll}0 & 63 & 115 & 178 & 218 & 281 & 333 & 396 & 459 & 499 & 562 & 614 & 677\end{array}$ & 0.0463 & 0 & 0 & 8 \\
\hline 441 & 1 & -1 & -1 & 3 & 41 & 34 & 26 & $\begin{array}{lllllllllllll}0 & 41 & 75 & 116 & 142 & 183 & 217 & 258 & 299 & 325 & 366 & 400 & 441 \\
\end{array}$ & 0.0503 & 0 & 0 & 9 \\
\hline 53 & 0 & 0 & 1 & 1 & 5 & 4 & 3 & 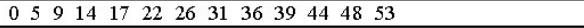 & 0.0504 & 0 & 0 & 10 \\
\hline 1106 & 2 & -1 & 0 & 5 & 103 & 85 & 65 & $\begin{array}{llllllllllllll}0 & 103 & 188 & 291 & 356 & 459 & 544 & 647 & 750 & 815 & 918 & 1003 & 1106\end{array}$ & 0.0526 & 0 & 0 & 11 \\
\hline 171 & 0 & 1 & 1 & 2 & 16 & 13 & 10 & $\begin{array}{llllllllllllll}0 & 16 & 29 & 45 & 55 & 71 & 84 & 100 & 116 & 126 & 142 & 155 & 171 \\
\end{array}$ & 0.0585 & 0 & 0 & 12 \\
\hline 848 & 1 & 2 & 0 & 5 & 79 & 65 & 50 & $\begin{array}{lllllllllllll}0 & 79 & 144 & 223 & 273 & 352 & 417 & 496 & 575 & 625 & 704 & 769 & 848\end{array}$ & 0.0611 & 0 & 0 & 13 \\
\hline 65 & 0 & 1 & -1 & 2 & 6 & 5 & 4 & $\begin{array}{llllllllllllll}0 & 6 & 11 & 17 & 21 & 27 & 32 & 38 & 44 & 48 & 54 & 59 & 65\end{array}$ & 0.0614 & 0 & 0 & 14 \\
\hline 236 & 0 & 2 & 0 & 4 & 22 & 18 & 14 & $\begin{array}{llllllllllllll}0 & 22 & 40 & 62 & 76 & 98 & 116 & 138 & 160 & 174 & 196 & 214 & 236 \\
\end{array}$ & 0.0649 & 0 & 0 & 15 \\
\hline 665 & 1 & 0 & 1 & 2 & 62 & 51 & 39 & $\begin{array}{lllllllllllll}0 & 62 & 113 & 175 & 214 & 276 & 327 & 389 & 451 & 490 & 552 & 603 & 665 \\
\end{array}$ & 0.0656 & 0 & 0 & 16 \\
\hline 783 & 1 & 1 & 1 & 3 & 73 & 60 & 46 & $\begin{array}{lllllllllllll}0 & 73 & 133 & 206 & 252 & 325 & 385 & 458 & 531 & 577 & 650 & 710 & 783\end{array}$ & 0.0694 & 0 & 0 & 17 \\
\hline 795 & 1 & 2 & -1 & 6 & 74 & 61 & 47 & $\begin{array}{llllllllllllll}0 & 74 & 135 & 209 & 256 & 330 & 391 & 465 & 539 & 586 & 660 & 721 & 795\end{array}$ & 0.0715 & 0 & 0 & 18 \\
\hline 1118 & 2 & 0 & -2 & 8 & 104 & 86 & 66 & $\begin{array}{lllllllllllll}0 & 104 & 190 & 294 & 360 & 464 & 550 & 654 & 758 & 824 & 928 & 1014 & 1118\end{array}$ & 0.0717 & 0 & 0 & 19 \\
\hline 376 & 1 & -2 & 0 & 5 & 35 & 29 & 22 & $\begin{array}{lllllllllllll}0 & 35 & 64 & 99 & 121 & 156 & 185 & 220 & 255 & 277 & 312 & 341 & 376 \\
\end{array}$ & 0.072 & 0 & 0 & 20 \\
\hline 935 & 2 & -2 & -1 & 9 & 87 & 72 & 55 & $\begin{array}{llllllllllllll}0 & 87 & 159 & 246 & 301 & 388 & 460 & 547 & 634 & 689 & 776 & 848 & 935 \\
\end{array}$ & 0.0765 & 0 & 0 & 21 \\
\hline 323 & 1 & -2 & -1 & 6 & 30 & 25 & 19 & $\begin{array}{lllllllllllll}0 & 30 & 55 & 85 & 104 & 134 & 159 & 189 & 219 & 238 & 268 & 293 & 323 \\
\end{array}$ & 0.0767 & 0 & 0 & 22 \\
\hline 547 & 1 & -1 & 1 & 3 & 51 & 42 & 32 & $\begin{array}{lllllllllllll}0 & 51 & 93 & 144 & 176 & 227 & 269 & 320 & 371 & 403 & 454 & 496 & 547\end{array}$ & 0.0767 & 0 & 0 & 23 \\
\hline 289 & 0 & 2 & 1 & 5 & 27 & 22 & 17 & $\begin{array}{lllllllllllll}0 & 27 & 49 & 76 & 93 & 120 & 142 & 169 & 196 & 213 & 240 & 262 & 289 \\
\end{array}$ & 0.0801 & 0 & 0 & 24 \\
\hline 1000 & 2 & -1 & -2 & 9 & 93 & 77 & 59 & $\begin{array}{lllllllllllllll}0 & 93 & 170 & 263 & 322 & 415 & 492 & 585 & 678 & 737 & 830 & 907 & 1000\end{array}$ & 0.0811 & 0 & 0 & 25 \\
\hline 988 & 2 & -2 & 0 & 8 & 92 & 76 & 58 & 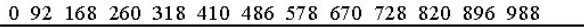 & 0.0816 & 0 & 0 & 26 \\
\hline 183 & 0 & 2 & -1 & 5 & 17 & 14 & 11 & 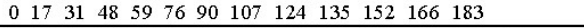 & 0.0843 & 0 & 0 & 27 \\
\hline 506 & 1 & 0 & -2 & 5 & 47 & 39 & 30 & $\begin{array}{llllllllllllll}0 & 47 & 86 & 133 & 163 & 210 & 249 & 296 & 343 & 373 & 420 & 459 & 506 \\
\end{array}$ & 0.0861 & 0 & 0 & 28 \\
\hline 901 & 1 & 2 & 1 & 6 & 84 & 69 & 53 & $\begin{array}{lllllllllllll}0 & 84 & 153 & 237 & 290 & 374 & 443 & 527 & 611 & 664 & 748 & 817 & 901 \\
\end{array}$ & 0.0862 & 0 & 0 & 29 \\
\hline 624 & 1 & 1 & -2 & 6 & 58 & 48 & 37 & $\begin{array}{lllllllllllll}0 & 58 & 106 & 164 & 201 & 259 & 307 & 365 & 423 & 460 & 518 & 566 & 624\end{array}$ & 0.0919 & 0 & 0 & 30 \\
\hline 388 & 1 & -1 & -2 & 6 & 36 & 30 & 23 & $\begin{array}{lllllllllllll}0 & 36 & 66 & 102 & 125 & 161 & 191 & 227 & 263 & 286 & 322 & 352 & 388 \\
\end{array}$ & 0.0921 & 0 & 0 & 31 \\
\hline 1159 & 2 & -1 & 1 & 6 & 108 & 89 & 68 & $\begin{array}{lllllllllllll}0 & 108 & 197 & 305 & 373 & 481 & 570 & 678 & 786 & 854 & 962 & 1051 & 1159\end{array}$ & 0.0922 & 0 & 0 & 32 \\
\hline 966 & 1 & 3 & 0 & 10 & 90 & 74 & 57 & $\begin{array}{lllllllllllll}0 & 90 & 164 & 254 & 311 & 401 & 475 & 565 & 655 & 712 & 802 & 876 & 966\end{array}$ & 0.0929 & 0 & 0 & 33 \\
\hline 354 & 0 & 3 & 0 & 9 & 33 & 27 & 21 & 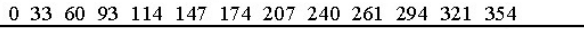 & 0.0974 & 0 & 0 & 34 \\
\hline 429 & 1 & -2 & 1 & 6 & 40 & 33 & 25 & $\begin{array}{lllllllllllll}0 & 40 & 73 & 113 & 138 & 178 & 211 & 251 & 291 & 316 & 356 & 389 & 429 \\
\end{array}$ & 0.0979 & 0 & 0 & 35 \\
\hline 882 & 2 & -2 & -2 & 12 & 82 & 68 & 52 & $\begin{array}{llllllllllllll}0 & 82 & 150 & 232 & 284 & 366 & 434 & 516 & 598 & 650 & 732 & 800 & 882\end{array}$ & 0.1006 & 0 & 0 & 36 \\
\hline 106 & 0 & 0 & 2 & 4 & 10 & 8 & 6 & $\begin{array}{lllllllllllll}0 & 10 & 18 & 28 & 34 & 44 & 52 & 62 & 72 & 78 & 88 & 96 & 106 \\
\end{array}$ & 0.1009 & 0 & 0 & 37 \\
\hline 913 & 1 & 3 & -1 & 11 & 85 & 70 & 54 & 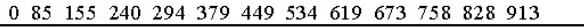 & 0.1009 & 0 & 0 & 38 \\
\hline 258 & 1 & -3 & 0 & 10 & 24 & 20 & 15 & $\begin{array}{lllllllllllll}0 & 24 & 44 & 68 & 83 & 107 & 127 & 151 & 175 & 190 & 214 & 234 & 258 \\
\end{array}$ & 0.104 & 0 & 0 & 39 \\
\hline 224 & 0 & 1 & 2 & 5 & 21 & 17 & 13 & \begin{tabular}{lllllllllllll|}
0 & 21 & 38 & 59 & 72 & 93 & 110 & 131 & 152 & 165 & 186 & 203 & 224 \\
\end{tabular} & 0.1043 & 0 & 0 & 40 \\
\hline 205 & 1 & -3 & -1 & 11 & 19 & 16 & 12 & $\begin{array}{lllllllllllll}0 & 19 & 35 & 54 & 66 & 85 & 101 & 120 & 139 & 151 & 170 & 186 & 205 \\
\end{array}$ & 0.1065 & 0 & 0 & 41 \\
\hline 407 & 0 & 3 & 1 & 10 & 38 & 31 & 24 & $\begin{array}{lllllllllllll}0 & 38 & 69 & 107 & 131 & 169 & 200 & 238 & 276 & 300 & 338 & 369 & 407\end{array}$ & 0.1073 & 0 & 0 & 42 \\
\hline 12 & 0 & 1 & -2 & 5 & 1 & 1 & 1 & $\begin{array}{llllllllllllll}0 & 1 & 2 & 3 & 4 & 5 & 6 & 7 & 8 & 9 & 10 & 11 & 12 \\
\end{array}$ & 0.1076 & 0 & 3 & 43 \\
\hline 742 & 1 & 2 & -2 & 9 & 69 & 57 & 44 & $\begin{array}{lllllllllllll}0 & 69 & 126 & 195 & 239 & 308 & 365 & 434 & 503 & 547 & 616 & 673 & 742\end{array}$ & 0.1076 & 0 & 0 & 44 \\
\hline 270 & 1 & -2 & -2 & 9 & 25 & 21 & 16 & $\begin{array}{lllllllllllll}0 & 25 & 46 & 71 & 87 & 112 & 133 & 158 & 183 & 199 & 224 & 245 & 270 \\
\end{array}$ & 0.108 & 0 & 0 & 45 \\
\hline 817 & 2 & -3 & -1 & 14 & 76 & 63 & 48 & 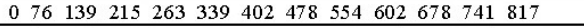 & 0.1081 & 0 & 0 & 46 \\
\hline 1019 & 1 & 3 & 1 & 11 & 95 & 78 & 60 & $\begin{array}{lllllllllllll}0 & 95 & 173 & 268 & 328 & 423 & 501 & 596 & 691 & 751 & 846 & 924 & 1019\end{array}$ & 0.1103 & 0 & 0 & 47 \\
\hline 301 & 0 & 3 & -1 & 10 & 28 & 23 & 18 & 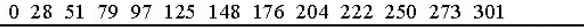 & 0.112 & 0 & 0 & 48 \\
\hline 1041 & 2 & -2 & 1 & 9 & 97 & 80 & 61 & $\begin{array}{lllllllllllll}0 & 97 & 177 & 274 & 335 & 432 & 512 & 609 & 706 & 767 & 864 & 944 & 1041 \\
\end{array}$ & 0.1121 & 0 & 0 & 49 \\
\hline 870 & 2 & -3 & 0 & 13 & 81 & 67 & 51 & $\begin{array}{lllllllllllll}0 & 81 & 148 & 229 & 280 & 361 & 428 & 509 & 590 & 641 & 722 & 789 & 870\end{array}$ & 0.1125 & 0 & 0 & 50 \\
\hline 718 & 1 & 0 & 2 & 5 & 67 & 55 & 42 & $\begin{array}{lllllllllllll}0 & 67 & 122 & 189 & 231 & 298 & 353 & 420 & 487 & 529 & 596 & 651 & 718\end{array}$ & 0.1159 & 0 & 0 & 51 \\
\hline 342 & 0 & 2 & 2 & 8 & 32 & 26 & 20 & 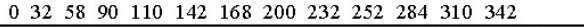 & 0.1171 & 0 & 0 & 52 \\
\hline 836 & 1 & 1 & 2 & 6 & 78 & 64 & 49 & $\begin{array}{lllllllllllll}0 & 78 & 142 & 220 & 269 & 347 & 411 & 489 & 567 & 616 & 694 & 758 & 836 \\
\end{array}$ & 0.1174 & 0 & 0 & 53 \\
\hline 1065 & 2 & 0 & -3 & 13 & 99 & 82 & 63 & $\begin{array}{lllllllllllll}0 & 99 & 181 & 280 & 343 & 442 & 524 & 623 & 722 & 785 & 884 & 966 & 1065 \\
\end{array}$ & 0.1218 & 0 & 0 & 54 \\
\hline 130 & 0 & 2 & -2 & 8 & 12 & 10 & 8 & $\begin{array}{lllllllllllll}0 & 12 & 22 & 34 & 42 & 54 & 64 & 76 & 88 & 96 & 108 & 118 & 130 \\
\end{array}$ & 0.1228 & 0 & 0 & 55 \\
\hline 600 & 1 & -1 & 2 & 6 & 56 & 46 & 35 & 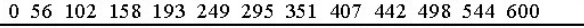 & 0.1233 & 0 & 0 & 56 \\
\hline 311 & 1 & -3 & 1 & 11 & 29 & 24 & 18 & $\begin{array}{lllllllllllll}0 & 29 & 53 & 82 & 100 & 129 & 153 & 182 & 211 & 229 & 258 & 282 & 311 \\
\end{array}$ & 0.1241 & 0 & 0 & 57 \\
\hline 1084 & 1 & 4 & 0 & 17 & 101 & 83 & 64 & $\begin{array}{lllllllllllll}0 & 101 & 184 & 285 & 349 & 450 & 533 & 634 & 735 & 799 & 900 & 983 & 1084\end{array}$ & 0.1251 & 0 & 0 & 58 \\
\hline 1183 & 2 & 1 & -3 & 14 & 110 & 91 & 70 & $\begin{array}{llllllllllllll}0 & 110 & 201 & 311 & 381 & 491 & 582 & 692 & 802 & 872 & 982 & 1073 & 1183 \\
\end{array}$ & 0.1252 & 0 & 0 & 59 \\
\hline 764 & 2 & -3 & -2 & 17 & 71 & 59 & 45 & $\begin{array}{lllllllllllll}0 & 71 & 130 & 201 & 246 & 317 & 376 & 447 & 518 & 563 & 634 & 693 & 764 \\
\end{array}$ & 0.1256 & 0 & 0 & 60 \\
\hline 1083 & 5 & -19 & 5 & 411 & 101 & 84 & 62 & $\begin{array}{lllllllllllll}0 & 101 & 185 & 286 & 348 & 449 & 533 & 634 & 735 & 797 & 898 & 982 & 1083\end{array}$ & 0.734 & 6 & 0 & 1188 \\
\hline 83 & 3 & -18 & 7 & 382 & 8 & 7 & 3 & 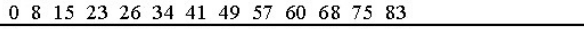 & 0.7356 & 6 & 1 & 1189 \\
\hline 88 & -3 & 19 & -6 & 406 & 8 & 6 & 7 & $\begin{array}{lllllllllllll}0 & 8 & 14 & 22 & 29 & 37 & 43 & 51 & 59 & 66 & 74 & 80 & 88 \\
\end{array}$ & 0.7359 & 6 & 4 & 1190 \\
\hline 1088 & -1 & 18 & -8 & 389 & 101 & 83 & 66 & $\begin{array}{lllllllllllll}0 & 101 & 184 & 285 & 351 & 452 & 535 & 636 & 737 & 803 & 904 & 987 & 1088 \\
\end{array}$ & 0.7401 & 6 & 0 & 1191 \\
\hline 524 & 4 & -19 & 6 & 413 & 49 & 41 & 29 & 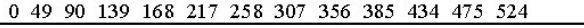 & 0.7479 & 6 & 0 & 1192 \\
\hline 695 & 4 & -18 & 7 & 389 & 65 & 54 & 39 & $\begin{array}{llllllllllllll}0 & 65 & 119 & 184 & 223 & 288 & 342 & 407 & 472 & 511 & 576 & 630 & 695 \\
\end{array}$ & 0.7484 & 6 & 0 & 1193 \\
\hline 647 & -2 & 19 & -7 & 414 & 60 & 49 & 40 & 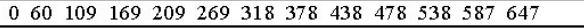 & 0.7508 & 6 & 0 & 1194 \\
\hline 476 & -2 & 18 & -8 & 392 & 44 & 36 & 30 & $\begin{array}{lllllllllllll}0 & 44 & 80 & 124 & 154 & 198 & 234 & 278 & 322 & 352 & 396 & 432 & 476 \\
\end{array}$ & 0.753 & 6 & 0 & 1195 \\
\hline 1136 & 5 & -19 & 6 & 422 & 106 & 88 & 65 & $\begin{array}{lllllllllllll}0 & 106 & 194 & 300 & 365 & 471 & 559 & 665 & 771 & 836 & 942 & 1030 & 1136\end{array}$ & 0.7599 & 6 & 0 & 1196 \\
\hline 35 & -3 & 19 & -7 & 419 & 3 & 2 & 4 & $\begin{array}{lllllllllllll}0 & 3 & 5 & 8 & 12 & 15 & 17 & 20 & 23 & 27 & 30 & 32 & 35 \\
\end{array}$ & 0.7632 & 6 & 4 & 1197 \\
\hline 577 & 4 & -19 & 7 & 426 & 54 & 45 & 32 & $\begin{array}{lllllllllllll}0 & 54 & 99 & 153 & 185 & 239 & 284 & 338 & 392 & 424 & 478 & 523 & 577\end{array}$ & 0.7757 & 6 & 0 & 1198 \\
\hline 594 & -2 & 19 & -8 & 429 & 55 & 45 & 37 & $\begin{array}{lllllllllllll}0 & 55 & 100 & 155 & 192 & 247 & 292 & 347 & 402 & 439 & 494 & 539 & 594\end{array}$ & 0.7798 & 6 & 0 & 1199 \\
\hline 1189 & 5 & -19 & 7 & 435 & 111 & 92 & 68 & $\begin{array}{lllllllllllll}0 & 111 & 203 & 314 & 382 & 493 & 585 & 696 & 807 & 875 & 986 & 1078 & 1189\end{array}$ & 0.7883 & 6 & 0 & 1200 \\
\hline
\end{tabular}


The numbers 53 and 118 are relatively prime. Therefore, every integer can be written in the format $n=x \cdot 53+y \cdot 118$ [36]. It is important to note that the strong restrictions on the coefficients $x, y, z$ are responsible for the feature that the intervals of the log-compatible consistent chromatic scales can be calculated as described. For example, if the condition on $z$ were weakened to $-8 \leq z \leq 8$, the numbers 306 and 918 could be written in two ways as combinations of 612, 118 and 53:

$306=-118+8 \cdot 53=612+118-8 \cdot 53$ and $918=612-118+8 \cdot 53=2 \cdot 612+118-8 \cdot 53$

Only the combinations with $z=-8$ result in the correct log-compatible semitones, if the formulas for $a, b$ and $c$ are applied. Newton's chromatic scale has a particularly weak approximation in 306-EDO, although it is well suited to approximate Pythagorean tuning [37], and also 918-EDO has very large deviations.

The coordinates highlighted grey in Table 11 are located in the smallest cuboid of Figure 12. The column "rnk" (rank) is calculated with $x^{2}+y^{2}+z^{2}$. The incompatibility index cmpt measures the total deviations from the scale defined through direct log-approximation in $n$-EDO units. For the definition of the consistency levels cns, see Table 10 . The integer triplets $(x, y, z)$ correspond to points in a three-dimensional space. It can be shown that within a cuboid grid of the dimensions $7 \times 38 \times 15$ [38] the representation of a number $n$ in the format $n=x \cdot 612+y \cdot 118+z \cdot 53$ is unique and that there are no larger cuboids with this property. The results of the geometrical analysis are summarized and visualized in Figure 12.

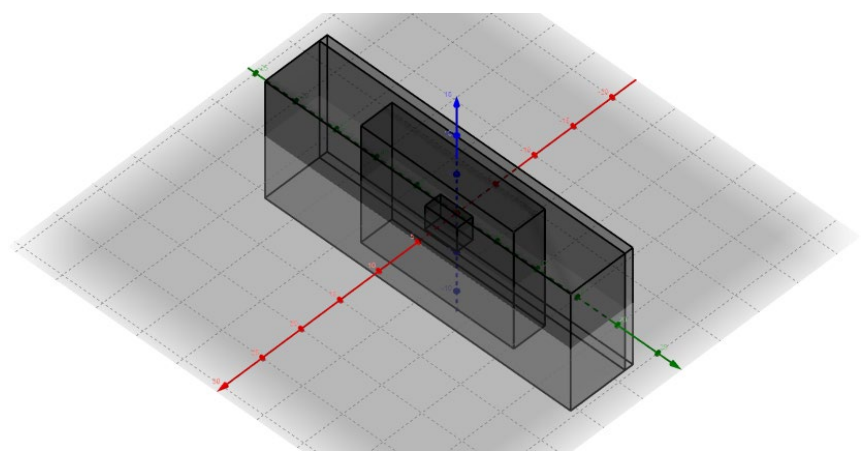

Figure 12. Four nested cuboids for $n$ up to 1200 . They are defined by the following ranges of $x, y$ and $z$. $[0,2][-2,2][-2,1]: 60$ points; contains the numbers $n$ of the 32 scales with the lowest deviations $[-1,3][-9,10][-8,7]: 1600$ points; contains the numbers $n$ of the 374 compatible scales $[-2,5][-19,19][-8,7]: 4992$ points; maximum cuboid with unique representation of $n$ (1153 scales) $[-3,5][-19,19][-8,7]: 5616$ points; contains all numbers $n$ up to $1200 ; 12$ ambiguous representations

The incompatibility index (cmpt) measures the deviation of a given representation of the syntonic chromatic scale from the best logarithmic pitch values. It is defined as the sum of the individual absolute deviations in $n$-EDO units, so that an index of 0 is perfect compatibility. There are 372 numbers $n$ between 12 and 1200 with the incompatibility index 0, which means that the related scales agree with the direct logarithmic approximations, and 13 scales have the maximum log-incompatibility index of 7.

There are 356 scales with $n$ between 12 and 1200 which are strongly consistent and log-compatible at the same time. Only 16 compatible scales have consistency levels greater than 0 - none of these values is greater than 3. The corresponding octave dividers $n$ are listed in Table 12.

Table 12. List of the log-compatible scales $(\mathrm{cmpt}=0)$ with consistency levels (cns) greater than 0.

\begin{tabular}{ccl}
\hline cns & cmpt & $n$ \\
\hline 1 & 0 & $29,41,63,82$ \\
2 & 0 & $\mathbf{7}, 19,31,43,55$ \\
3 & 0 & $\mathbf{1 0}, 12,22,24,34,36,46,56,58$ \\
\hline
\end{tabular}


The lowest deviation 0.273 for a log-incompatible scale occurs at $n=920$ and the highest deviation of 0.3912 for a log-compatible scale at $n=306$. In other words, the root mean square deviation does not fully separate compatible from incompatible scales. It is decisive only for deviations less than 0.273 and for deviations greater than 0.3912 .

A simple ranking of the representations $n=x \cdot 512+y \cdot 118+z \cdot 53$ is defined by the Euclidean norm, $d=\sqrt{x^{2}+y^{2}+z^{2}}$ the distance of the point $(x, y, z)$ from the origin $(0,0,0)$ and it corresponds to the square root of the column rnk in Table 11. Low values of $d$ correlate to low deviations (dev) of the $n$-EDO chromatic scales from the syntonic chromatic scale. The graphs in Figures $13 \mathrm{a} / 13 \mathrm{~b}$ show that the coordinates $x, y, z$ of a number $n$ can be used to estimate the quality of the fit of an $n$-EDO system with the syntonic chromatic scale. However, there is no monotone relationship between Euclidean norms of these points and the corresponding root mean square deviations.

\section{dev depending on Euclidean norm}

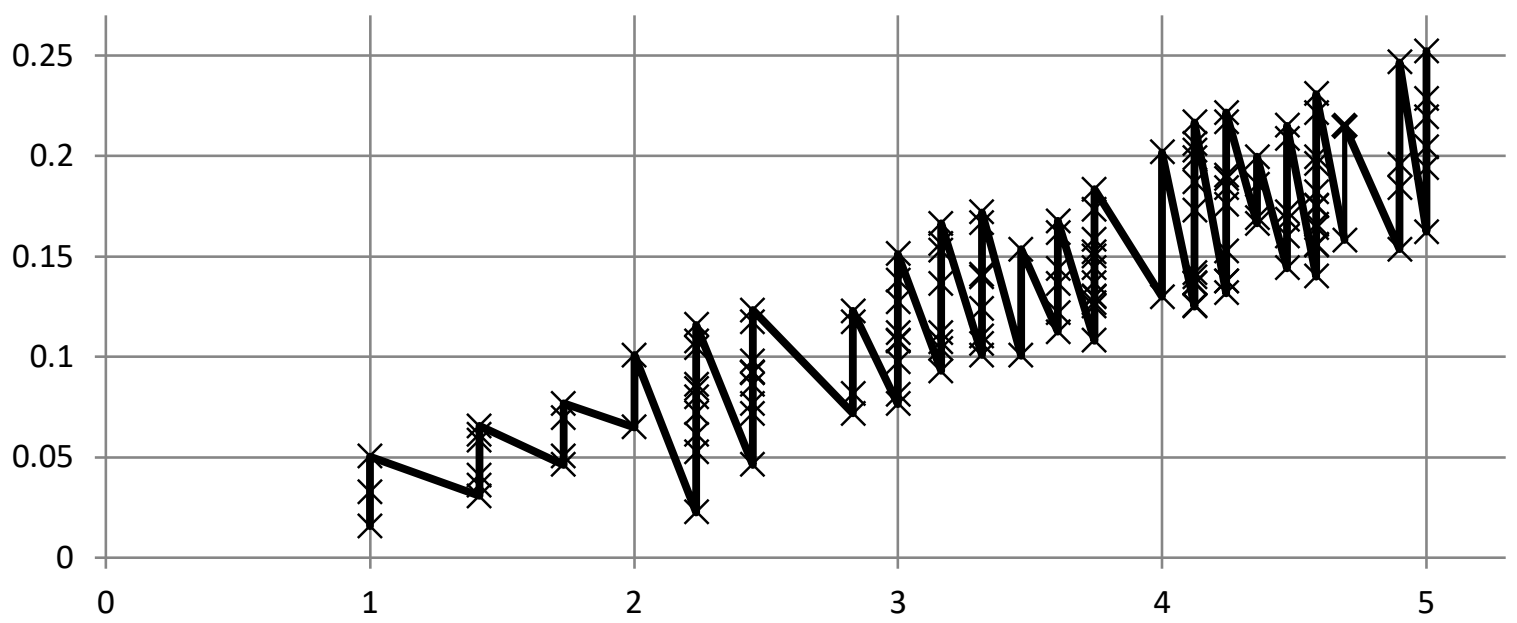

Figure 13a. The horizontal axis of this plot measures the distance of points $(x, y, z)$ from the origin $(0,0,0)$, and the vertical measures deviations in $n$-EDO fits. Points on the same vertical line are located on the same spheres about the origin. Neither the related coordinates nor the corresponding numbers $n$ of the points between the spheres of radius 1 and 5 are indicated. The three points on the unit sphere represent the best EDOs with $n=53, n=118$ and $n=612$.

\section{dev depending on Euclidean norm}

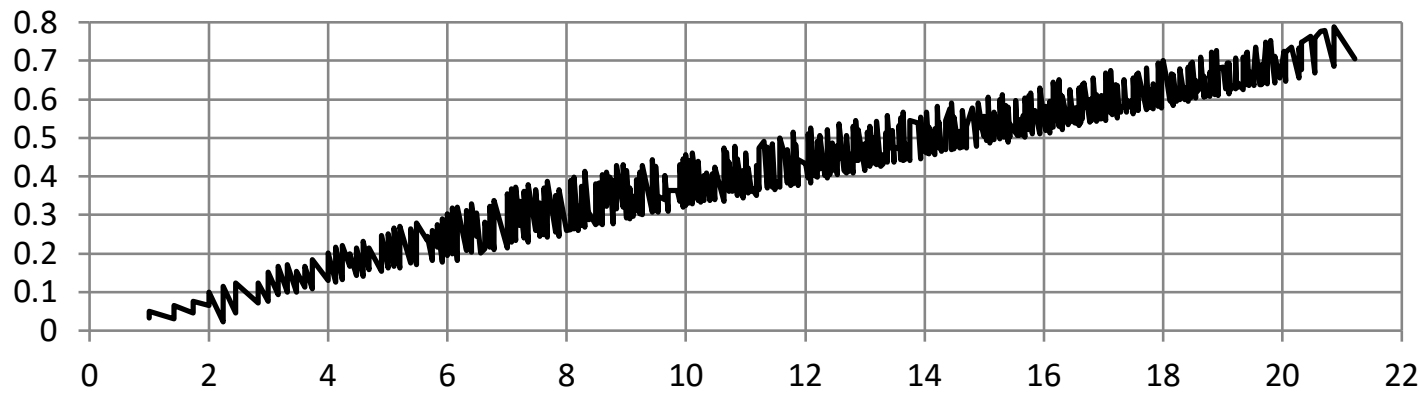

Figure 13b. As Figure 13a but with sphere radiuses up to 21. The configuration is in a good linear correlation.

The two curves in Figure 14 show that the Euclidean norms $d=\sqrt{x^{2}+y^{2}+z^{2}}$ of $n=x \cdot 512+y$. $118+z \cdot 53$ (norm: blue) and the deviations of their $n$-EDO representation from the syntonic chromatic scale (rms_u: red) form very similar patterns. This means that the coordinates $(x, y, z)$ explain the quasi-chaotic dependence on $n$ of the deviations to a wide extent. Both graphs have pronounced minima at $12,53,53 \pm 12$ 
as well as at $118,118 \pm 12$. Some of the strong maxima (indicating inaccurate approximations) occur at 47 , $47 \pm 12$. Recall that $118=2 \cdot 53+12=65+53=2 \cdot 59$ and that the poor 59 (rejected by Newton, see Figure $9 a)$, is exactly in the middle between the pronounced minima at 53 and 65 .

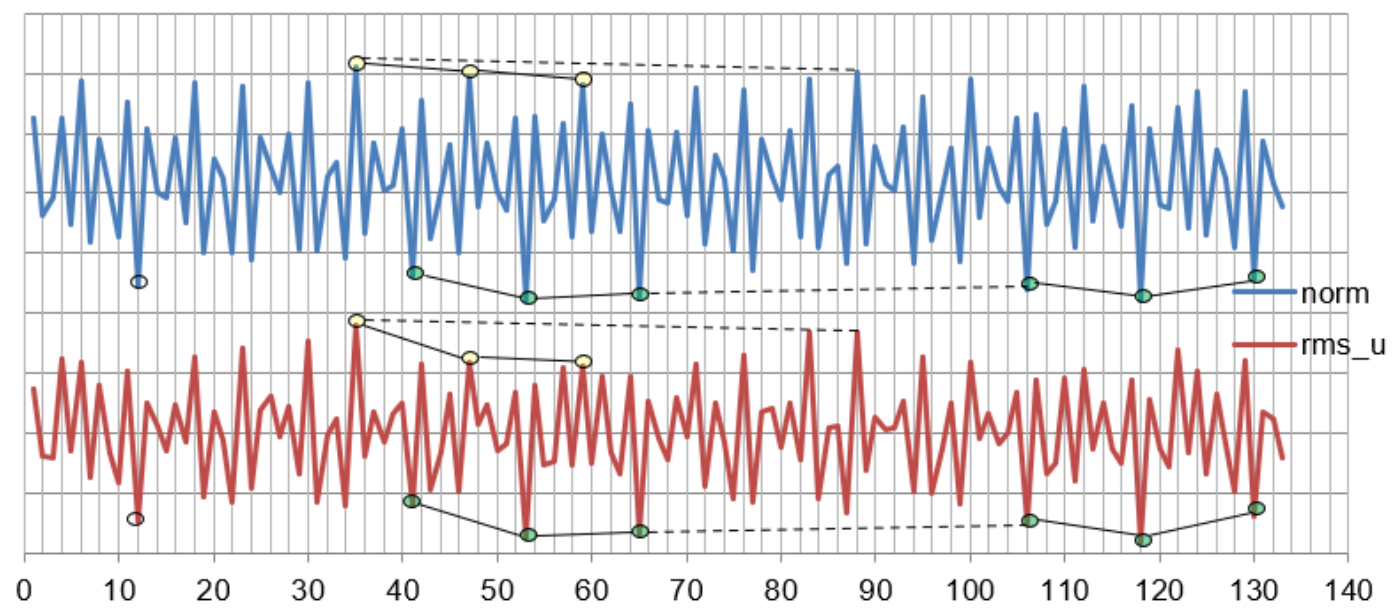

Figure 14. The diagram shows the Euclidean norm (above) of the combinations $n=x \cdot 612+y \cdot 118+z$. 53 and the root mean square deviations of the corresponding consistent $n$-EDO representation from the syntonic chromatic scale for values of $n<134$. Pronounced maxima and minima are highlighted. Maxima correspond to weak and minima to accurate approximations [39].

\section{CONCLUSION}

The controversies about syntonic pitch systems and their many ambiguities, as well as the presence of various tempered tunings in the $16^{\text {th }}$ century and later, demanded mathematical skills and powerful tools to compare the related scales and the sizes of the many different intervals efficiently. Accurate tables of logarithms were published in the early $17^{\text {th }}$ century. The use of equal divisions of the octave to measure pitch systems was advanced by Simon Stevin, Marin Mersenne, Nicolaus Mercator, Christiaan Huygens, Isaac Newton and others. The basic idea was to find fine grained "meta-scales" (lowest common denominators) which could express the scales under consideration as subsets very accurately. Newton found two of the three best metascales for limit-5 chromatic scales among the equal divisions of the octave with less than 1783 parts.

It is unlikely that the division of the octave into 612 equal parts could have been found without using a logarithm table. However, the division into 53 parts, which is at the same time an optimum for the Pythagorean tuning, could have been found with the knowledge of Boethius. Jacobus Leodiensis in the $14^{\text {th }}$ century proposed a monochord of 53 commas only, a scale with 41 Pythagorean commas and 12 intervals a little smaller [40]. My tentative reconstruction of Newton's implicit line of reasoning shows how his various chromatic EDO-approximations can be derived from the 612-EDO representation of the chromatic scale with no need for further logarithms.

The reconstruction of Newton's approach to the tuning problem led to some more general mathematical considerations in the final part of this article. I have shown that the optimum divisions of the octave into 53, 118 and 612 equal parts can be used to generate a comprehensive collection of consistent $n$ EDO scales for arbitrary divisions of the octave with up to $n=1200$ equal parts. This collection contains the scales which agree with direct rounding as a subset. The interpretation of the related numbers $n$ as points in a three-dimensional space revealed an almost linear relationship between their distance from the origin and the quality of the related $n$-EDO representation of the syntonic chromatic scale. The required calculations rely only on the knowledge of three optimum equal divisions, 53-EDO, 118-EDO and 612-EDO - the key to the large data sets added to this text is hidden in Newton's analysis of the chromatic scale given in Figure 6a.

\section{ACKNOWLEDGEMENTS}

This text is based on research made for the project "Sound Colour Space - A Virtual Museum" (2015-2016) at Zurich University of the Arts, funded by the Swiss National Science Foundation (105216_156979). The 
author wishes to thank Martin Neukom, Benjamin Wardhaugh and Roman Oberholzer for their critical and helpful comments. Furthermore, the insightful comments and suggestions by the reviewers helped a lot to improve my contribution and find its final form. This article was copyedited by Matthew Moore and layout edited by Diana Kayser.

\section{NOTES}

[1] Correspondence can be addressed to: Dr. Daniel Muzzulini, Bläsiring 42, CH-4057 Basel, daniel@muzzulini.ch.

[2] Wardhaugh (2013, pp. 85-113). The College Notebook (MS Add.4000), Cambridge University Library, Manuscript 225, is also published online $<\mathrm{http}$ ://cudl.lib.cam.ac.uk/view/MS-ADD-04000/1 > [visited 202004-28]

[3] EDO stands for Equal Division of the Octave; 12-EDO is equal temperament with 12 pitches per octave.

[4] Comparable statements holding "to a great extent" are frequently given in perceptual psychology, where some (two or three) main factors are determined that would explain a complex phenomenon such as musical timbre by projecting experimental data to a low dimensional structure.

[5] A monochord is an experimental device (or musical instrument) with a single string that can be divided with moveable bridges in order to study the relationships between musical intervals.

[6] This is a misleading designation, because the Pythagorean chromatic and enharmonic genera and systems (as for example described and transmitted by Boethius) had interval ratios containing higher prime numbers. In the course of the history they disappeared and the medieval modes were usually constructed on base of proper diatonic tetrachords and hexachords only.

[7] The full Greek systems (systema teleion) have two different octaves; only the upper octave contains both $\mathrm{Bb}$ and $\mathrm{B}$.

[8] The combinations lead to just minor thirds (6:5) and two different whole tone steps $(9: 8$ and $10: 9)$.

[9] Vincenzo Galilei and Gioseffo Zarlino in the $16^{\text {th }}$ century used the term "Sintono di Tolomei" for the just intonation diatonic scale. Limit-5 pitches of the same name differ by syntonic commas, which are a little smaller than Pythagorean commas.

[10] One of these grids uses three rows of fifths, see Wardhaugh (2013, p. 161, p. 227)

[11] The use of musical number triangles in historical sources is discussed in Muzzulini (2015, 212-215)

[12] The continued fractions expansions are independent of the base of the underlying number system. Irrational numbers correspond with infinite continued fractions (Euclid's algorithm does not come to an end for irrational ratios), cf. Schechter (1980). The convergence of the continued fractions approximation to a given irrational number is comparably slow.

[13] It follows from Proposition 3 of the Euclidean "Sectio canonis" (Barker Ed. 1989, p. 195; Lindley \& Turner-Smith 1993, pp. 228-229).

[14] Continued fractions were used in music theoretical writings of the $18^{\text {th }}$ and $19^{\text {th }}$ centuries Lambert $(1774$, 59) and Drobisch (1852, 76), see also Carey, N., \& Clampitt, D. (1989, 197-198).

[15] See Barbour (1951), Žabka (2010; 2013), Muzzulini \& Vogtenhuber (2016)

[16] Wardhaugh (2013, pp. 1-84), Descartes $(1987,47)$ 
[17] I became aware of this diagram through a personal communication by Susan F. Weiss (1999). See also Snyder $(1983,1986)$.

[18] Gaukroger (1995, pp. 55-59). But Descartes did not treat meantone temperaments in his "Compendium musicae" or the tuning of lutes.

[19] The cent is a modern unit of interval size, so that the 12-edo semitone measures 100 cent and the octave therefore 1200 cent. To obtain cent values from Newton's values multiply his numbers by 100 .

[20] There are 118 classes of chromatic scales that can be written as uninterrupted chains of Pythagorean fifths $(3: 2)$ and small fifths $(40: 27)$. See also Žabka (2013). The Pythagorean chromatic 12-note scale has just two different semitones $(256: 243$ and $2187: 2048)$. By convention, the note names of chromatic semitones begin with the same letter and differ by a simple alteration, such as $\mathrm{C}-\mathrm{C} \#, \mathrm{Db}-\mathrm{D}$ or $\mathrm{F} \#-\mathrm{F} \# \#$, whereas the notes E-F, C\#-D, C-Dd or F\#\#-G\# form diatonic semitones. In syntonic chromatic scales the chromatic and/or diatonic semitones can occur in different varieties.

[21] See Barbour (1951), Muzzulini, D. \& Vogtenhuber (2016)

[22] Frequency is measured in Hertz, i.e., full periods per second. Mark Lindley looked at Newton's octave divisions more than 30 years ago and claimed the Newton favored 53-EDO over all other divisions (Lindley 1987, pp. 206-210).

[23] The curves are explained in Wardhaugh (2013, 96-97).

[24] If they were the same, they would be equal to 6 semitones of the 12-tempered tuning.

[25] The distinction between deviations with respect to the unit and absolute deviations (in cent) is crucial for the notion of quality of best fit used in this article.

[26] See http://sound-colour-space.zhdk.ch/diagrams/39

[27] It is even optimal for EDOs with a unit interval greater than 0.67 cent. The coarsest better approximation is 1783 -EDO, see Table 7.

[28] Later in this text the deviations are formally measured as root mean square deviations.

[29] According to Boethius, the interval of the Pythagorean comma is defined as six whole tones minus one octave. It has the ratio 531,441:524,228. Boethius (1867, 264-267: Inst. Mus. II, 31)

[30] Mercator's music theoretical manuscripts are published in Wardhaugh (2013, 129-236).

[31] Newton knew an interpretation of the Greek tetrachord's genera with syntonic intervals (Ptolemy, Zarlino) not looked at by Descartes.

[32] See Appendix_5 (http://hdl.handle.net/1811/92832) for detailed data about this point.

[33] Newton used the same abbreviations for the three semitones of his scale.

[34] If the condition $2 \mathrm{c}>\mathrm{a}$ is violated, the lesser chromatic semitone is more like a quartertone than a semitone.

[35] Although 12-EDO does not distinguish between different semitones at all, it is a consistent approximation to Newton's syntonic chromatic scales.

[36] This is a general property for pairs of relatively prime numbers, so that even 612 could be obtained from 53 and 118 only: 
[37] Notice that 306-EDO is related to 612-EDO as 59-EDO to 118-EDO. Both 306-EDO and 59-EDO give a "very poor" chromatic scale where some pitches are to be rounded by almost half an EDO unit. Newton did not give the full representation for 59-EDO, and he did not look at all at 306-EDO.

[38] The dimensions are given as side lengths of the cuboid not as numbers of grid points.

[39] The two graphs are differently scaled in the y-direction.

[40] Jacobus Leodiensis (ca. 1260 - after 1330), suggests and depicts a monochord with 53 micro-intervals per octave: 41 Pythagorean commas and 12 intervals a little smaller than the Pythagorean comma (Pythagorean semitones minus three Pythagorean commas), cf. Smits van Waesberghe (ed), (1988, p. 106, p. 139, f. 51r)

\section{REFERENCES}

Barbour, J. M. (1951). Tuning and temperament. A historical survey. East Lansing: Michigan State College Press, Da Capo Press: New York 1972

Barker, A. (1989 Ed.). Greek musical writings, Volume II Harmonic and Acoustic Theory, Cambridge: Cambridge University Press, 1989

Barkowsky, J. (2007). Mathematische Quellen der musikalischen Akustik. Wilhelmshaven : Florian Noetzel Verlag

Boethius, A. M. T. S. (1867). De institutione arithmetica libri duo: de institutione musica libri quinque. Ed. Godofredus Friedlein, Leipzig

Bürgi, J. (1620). Aritmetische und geometrische Progreß-Tabulen, Prague 1620

Carey, N., \& Clampitt, D. (1989). Aspects of Well-Formed Scales. Music Theory Spectrum, 11(2), 187-206. https://doi.org/10.2307/745935

Descartes, R. (1650). Renati Des-Cartes, Musicae Compendium. Strassbourg: Heitz

Descartes, R. (1987), Abrégé de musique. Compendium musicae. Traduit et introduit par Frédéric de Buzon Paris : Presses Universitaires de France

Drobisch, M. W. (1852). Über musikalische Tonbestimmung und Temperatur, Leipzig. Weidmannsche Buchhandlung

Euler, Leonhard. (1739). Tentamen novae theoriae musicae. St. Petersburg

Fludd, R. (1618/24). Utriusque cosmi historia, Vol I, Tract II, Part II, Lib. I, 1624 (first edition 1618)

Fogliano, L. (1529). Musica theorica. Venice: Io. Antonius et Fratres de Sabio, 1529

Galilei, V. (1581). Dialogo di Vincentio Galilei ... della musica antica, et della moderna. Firenze

Gaukroger, S. (1995). Descartes: An Intellectual Biography. Oxford: Clarendon Press.

Hall, D. (1973). The Objective Measurement of Goodness-of-Fit for Tunings and Temperaments. In: Journal of Music Theory, Vol. 17, No. 2, pp. 274-290. https://doi.org/10.2307/843344

Holder, W. (1731). A treatise of the natural grounds, and principles, of harmony. London 1731 (first edition 1694) 
Huygens, C. (c. 1661). Divisio octavae in 31 intervalla aequalia. In: Oeuvres complètes de Christiaan Huygens, Tome 20, La Haye: Martinus Nijhoff 1940, 147-149

Jacobus Leodiensis, (s.a.) Compendium De Musica, Bruxelles, Bibliothèque Royale 10162-66. In: Ed. Smits van Waesberghe, J. et al. (1988). Jacobi Leodiensis - Tractatus De Consonantiis, Tractatus de Intonatione Tonorum, Compendium de Musica. Buren: Frits Knuf, 88-122, Facs. : 133-146

Jedrzejewski, F. (2018) Quirinus van Blankenburg's Transporteur. Journal of Mathematics and Music, 12:2, 123-124. https://doi.org/10.1080/17459737.2018.1478649

Kepler, J. (1619). Ioannis Keppleri Harmonices mundi libri V. Lincii, Austriae 1619. Lib III. https://doi.org/10.5479/sil.135810.39088002800316

Kircher, A. (1650). Musurgia Universalis. Rome: Ludovico Grignani

Mersenne, M. (1636). Harmonie Universelle, contenant la Theorie et la Pratique de la Musique. Livre Second, Des Dissonances. Paris

Lambert, J.-H. (1774). Remarques sur le tempérament en Musique. In Mémoires de l'Académie de Berlin, $1774,55-73$

Lindley, M. (1987). Stimmung und Temperatur. In: Hören, Messen und Rechnen in der frühen Neuzeit, Geschichte der Musiktheorie Bd. 6, 109-331. Darmstadt: Wissenschaftliche Buchgesellschaft

Mercator, N. (s.a.). Musical Notebook / Theoria Musices / Of Musick (1) / Of Musick (2). In: Wardhaugh (2013, pp 129-236)

Muzzulini, D. (2015). The geometry of musical logarithms. Acta Musicologica LXXXVII/2, 193-216

Muzzulini, D. (Ed. 2023). Sound Colour Space - The Art of Diagram. ZHdK (in prep.)

Muzzulini, D. \& Vogtenhuber R. (2016). Chromatic Scales. Retrieved from

http://sound-colour-space.zhdk.ch/exhibition/chromatic-scales

Newton, I. (1665). Of Musick. In College Notebook. MS Add. 4000, f. 138r-f. 143r. Cambridge University Library. Retrieved from http://cudl.lib.cam.ac.uk/view/MS-ADD-04000. All pictures from MS Add. 4000 are reproduced by kind permission of the Syndics of Cambridge University Library. Critically edited in: Wardhaugh (2013, pp. 85-113).

Newton, I. (1704). Opticks: Or, a Treatise of the Reflexions, Refractions, Inflexions and Colours of Light. London. https://doi.org/10.5479/sil.302475.39088000644674

Rameau, J.-P. (1726). Table des Progressions. Nouveau système de musique thèorique. Paris 1726, 24

Salinas, F. (1577). De musica libri septem. Mathias Gastius, Salamanca, 1577

Schechter, M. (1980). Tempered Scales and Continued Fractions. In: The American Mathematical Monthly, Vol. 87, No. 1, 40-42. https://doi.org/10.1080/00029890.1980.11994951

Snyder, J. L (1983). Theinred of Dover on Consonance: A Chapter in the History of Harmony. In: Music Theory Spectrum 5, pp. 110-120. https://doi.org/10.2307/746098

Snyder, J. L. (1986). Non-Diatonic Tones in Plainsong : Theinred of Dover versus Guido d'Arezzo. In : La musique et le rite sacré et profane. Strasbourg Vol. II pp. 49-67 
Stevin, S. (c. 1605). Van de Spiegheling der Singconst (ms). "Van de Spiegeling der Singconst" et "Van de Molens" : Deux traités inédits, Bierens de Haan, 1884

von Oettingen, A. (1917). Die Grundlagen der Musikwissenschaft und das duale Reininstrument. Leipzig. Hirzel, 1917

Waldvogel, J. (2014). Jost Bürgi and the discovery of the logarithms. In: Elemente der Mathematik, Volume 69.3, 89-117. https://doi.org/10.4171/EM/253

Wardhaugh, B. (2013 Ed.). The Compendium Musicae of René Descartes: Early English Responses. Musical Treatises. Turnhout: Brepols

Žabka, M. (2010). Well-formedness in two dimensions: a generalization of Carey and Clampitt's theorem. Journal of Mathematics and Music, Volume 4.1, 2010 - Issue 1.

https://doi.org/10.1080/17459737.2010.491975

Žabka M. (2013). The Minkowski Geometry of Numbers Applied to the Theory of Tone Systems. In: Yust J., Wild J., Burgoyne J.A. (eds) Mathematics and Computation in Music. MCM 2013. Lecture Notes in Computer Science, vol 7937. Springer, Berlin, Heidelberg. https://doi.org/10.1007/978-3-642-39357-0_18

Zarlino, G. (1562). Le istitutioni harmoniche. Venetia 1562 (first edition 1558)

Zarlino, G. (1588). Sopplimenti musicali. Venetia: Francesco de Franceschi, Sanese 